\title{
Concurrent Inhibition and Excitation of Phrenic Motoneurons during Inspiration: Phase-Specific Control of Excitability
}

\author{
M. A. Parkis, ${ }^{1}$ X.-W. Dong, ${ }^{2}$ J. L. Feldman, ${ }^{3}$ and G. D. Funk ${ }^{1}$ \\ ${ }^{1}$ Department of Physiology, Faculty of Medicine and Health Sciences, University of Auckland, Auckland, New Zealand, \\ 2Schering-Plow Research Institute, CNS/CV Research, Kenilworth, New Jersey 07033, and ${ }^{3}$ Systems Neurobiology \\ Laboratory, Departments of Neurobiology and Physiological Science, University of California Los Angeles, \\ Los Angeles, California 90095-1763
}

The movements that define behavior are controlled by motoneuron output, which depends on the excitability of motoneurons and the synaptic inputs they receive. Modulation of motoneuron excitability takes place over many time scales. To determine whether motoneuron excitability is specifically modulated during the active versus the quiescent phase of rhythmic behavior, we compared the input-output properties of phrenic motoneurons (PMNs) during inspiratory and expiratory phases of respiration.

In neonatal rat brainstem-spinal cord preparations that generate rhythmic respiratory motor outflow, we blocked excitatory inspiratory synaptic drive to PMNs and then examined their phase-dependent responses to superthreshold current pulses. Pulses during inspiration elicited fewer action potentials compared with identical pulses during expiration. This reduced excitability arose from an inspiratory-phase inhibitory input that hyperpolarized PMNs in the absence of excitatory inspiratory inputs. Local application of bicuculline blocked this inhibition as well as the difference between inspiratory and expiratory firing. Correspondingly, bicuculline locally applied to the midcervical spinal cord enhanced fourth cervical nerve (C4) inspiratory burst amplitude. Strychnine had no effect on C4 output. Nicotinic receptor antagonists neither potentiated C4 output nor blocked its potentiation by bicuculline, further indicating that the inhibition is not from recurrent inhibitory pathways. We conclude that it is bulbospinal in origin.

These data demonstrate that rapid changes in motoneuron excitability occur during behavior and suggest that integration of overlapping, opposing synaptic inputs to motoneurons is important in controlling motor outflow. Modulation of phasic inhibition may represent a means for regulating the transfer function of PMNs to suit behavioral demands.

Key words: phrenic motoneuron; brainstem; spinal cord; respiration; GABA; neonatal rat
Motoneurons shape motor patterns by transforming inputs into appropriate outputs controlling muscle contraction. This transformation of input into output, excitability, is determined by an interaction between synaptic inputs and the expression and modulation of intrinsic voltage- and ligand-gated conductances (Hultborn and Kiehn, 1992). Excitability is not static. It changes over multiple time scales (Feldman et al., 1990), such as during development (Berger et al., 1996) and in transitions between sleep states (Soja et al., 1991; Kubin et al., 1993). Because the output of multiple motoneuron pools must be coordinated to optimize movements for various behaviors, motoneuron properties may also change over faster time scales to achieve changes in excitability specific to a given behavior (Dickinson, 1995; Krawitz et al., 1997) or to a particular phase of behavior (Brownstone et al., 1992).

Various mechanisms could underlie such rapid changes in motoneuron excitability. (1) Coactivation of neuromodulatory pathways to motoneurons during behaviors is suggested by reductions in action potential threshold during fictive locomotion (Kra-

\footnotetext{
Received Oct. 20, 1998; revised Dec. 28, 1998; accepted Jan. 7, 1999.
}

This research was supported by grants from the Marsden Fund, the New Zealand Lottery Grants Board, the Health Research Council of New Zealand, and National Institutes of Health (Grant NS-24742). We thank Ms. C. Walsh, Dr. D. Robinson, and Mr. A. Frankcom-Burgess for excellent technical assistance.

Correspondence should be addressed to to Dr. M. A. Parkis, Department of Physiology, Faculty of Medicine and Health Science, University of Auckland, Private Bag 92019, Auckland, New Zealand.

Copyright (C) 1999 Society for Neuroscience $\quad 0270-6474 / 99 / 192368-13 \$ 05.00 / 0$ witz et al., 1997) and by monoamine-induced plateau potentials (Hounsgaard et al., 1988; Hounsgaard and Kiehn, 1989; Hultborn and Kiehn, 1992). (2) The strength of recurrent inhibitory pathways can be modulated (Hultborn et al., 1979; Hilaire et al., 1986). (3) The balance of concurrent excitatory and inhibitory synaptic inputs may be adjusted. Indirect evidence for such opposing inputs to hypoglossal motoneurons during inspiration (Withington-Wray et al., 1988; Woch and Kubin, 1995), and evidence for GABAergic gain modulation of respiratory premotoneurons (McCrimmon et al., 1997), led us to test whether concurrent inhibition and excitation underlie phase-specific modulation of motoneuron excitability.

Determining whether motoneuron excitability is differentially modulated between phases of a behavior requires preparations exhibiting behavior. Moreover, investigating motoneuron excitability during the active phase of behavior presents a challenge, because changes in membrane potential and input resistance produced by excitatory synaptic drive can mask underlying modulatory effects. For example, increased excitability of lumbar motoneurons during the active versus quiescent phase of the fictive locomotor cycle (Brownstone et al., 1992) suggests that activation of central rhythmic behavioral circuits changes the input-output function of motoneurons. However, interpretation of these results is confounded by the presence of ongoing rhythmic locomotor drive potentials and the associated changes in membrane conductance. In most rhythmic behaviors, block of these postsynaptic drive potentials to motoneurons will disrupt 
generation of behavioral rhythm, due to proximity of the motoneurons to the rhythm-generating circuitry (Robertson and Stein, 1988; Brownstone et al., 1992).

To address these problems and test for rapid, phase-specific modulation of motoneuron excitability, we used a neonatal rat brainstem-spinal cord preparation that generates rhythmic inspiratory drive to motoneurons (Smith and Feldman, 1987). This preparation was chosen because phrenic motoneurons (PMNs), which drive the diaphragm, are spatially segregated from the rhythm-generating networks that produce their primary behavioral (inspiratory) input, thereby facilitating pharmacological manipulation of fast excitatory inputs at the motoneuron level without disruption of respiratory rhythm. In addition, in vitro conditions allow complete block of excitatory postsynaptic rhythmic drive currents.

\section{MATERIALS AND METHODS}

Brainstem-spinal cord preparations. Experiments were performed on brainstem-spinal cord preparations $(n=74)$ from neonatal Wistar rats ranging in age from 0 to $3 \mathrm{~d}$ postnatal $(\mathrm{P} 0-\mathrm{P} 3)$. Preparations were isolated using methods previously described for Sprague Dawley rats (Smith and Feldman, 1987; Dong and Feldman, 1995). Briefly, an animal was anesthetized with diethyl ether and decerebrated, then the brainstem-spinal cord isolated in a dissection chamber containing artificial CSF (aCSF) containing (in mM): $128 \mathrm{NaCl}, 3 \mathrm{KCl}, 1.5 \mathrm{CaCl}_{2}, 1 \mathrm{MgSO}_{4}$, $21 \mathrm{NaHCO}_{3}, 0.5 \mathrm{NaH}_{2} \mathrm{PO}_{4}, 30$ D-glucose, $\mathrm{pH} 7.4$, at $20-22^{\circ} \mathrm{C}$, oxygenated with $95 \% \mathrm{O}_{2} / 5 \% \mathrm{CO}_{2}$. Preparations extended from the midpontine level rostrally to the seventh cervical segment caudally.

After isolation, the brainstem-spinal cord was pinned, ventral surface up, on Sylgard resin in a recording chamber ( $2 \mathrm{ml}$ volume) perfused with oxygenated aCSF at a flow rate of $2-2.5 \mathrm{ml} / \mathrm{min}$. The pia mater was then removed from the ventral surface of the spinal cord just lateral to midline at the level of the $\mathrm{C} 4$ nerve root to allow introduction of whole-cell recording electrodes into the PMN column and facilitate drug diffusion. Bath temperature was gradually increased to $26-27^{\circ} \mathrm{C}$ before recording.

Extracellular recording of whole-nerve inspiratory activity. Inspiratory motoneuron activity was recorded from the severed ends of $\mathrm{C} 1$ or $\mathrm{C} 4$ cervical roots using suction electrodes ( $80-100 \mu \mathrm{m}$ internal diameter). In experiments requiring block of glutamatergic drive to individual PMNs, C4 nerve output was also abolished. Thus $\mathrm{C} 1$ nerve output was recorded as an index of respiratory cycle timing. In experiments designed to determine the effect of drugs on PMN population output, we recorded from the C4 nerve. Nerve recordings were amplified (50,000 times), bandpass-filtered $(0.1-3 \mathrm{kHz})$, full wave-rectified, and integrated using a leaky integrator $(\tau=50 \mathrm{msec})$.

Whole-cell recording. Intracellular recordings from PMNs $(n=54)$ were made using "blind" whole-cell patch-clamp recording techniques (Blanton et al., 1989). Patch electrodes (resistance 4.0-5.5 M $\Omega ; 1.5-2 \mu \mathrm{m}$ tip size) were pulled on a horizontal puller (Sutter Model P-97) from 1.2 $\mathrm{mm}$ outer diameter, filamented borosilicate glass (Clark/WPI) and filled with solution containing (in $\mathrm{mM}$ ): $\mathrm{K}^{+}$-gluconate $125, \mathrm{NaCl} 5, \mathrm{CaCl}_{2} 1$, HEPES 10, BAPTA 10, ATP $\left(\mathrm{Mg}^{2+}\right.$ salt) 2. Intracellular solution $\mathrm{pH}$ was adjusted to 7.2-7.3 with $5 \mathrm{M} \mathrm{KOH}$. Signals were amplified and filtered with a patch-clamp amplifier (5 kHz Bessel filter, Axopatch 1D; Axon Instruments, Foster City, CA)

Series resistance and whole-cell capacitance were estimated under voltage-clamp conditions by using short voltage pulses $(100 \mathrm{~Hz},-10 \mathrm{mV}$, $3.0 \mathrm{msec}$ ). Series resistance ranged from 10 to $32 \mathrm{M} \Omega$, (mean, $17 \pm 6$ $\mathrm{M} \Omega$ ) and was monitored throughout experiments. Data were discarded if series resistance changed between control and test conditions. Voltagecurrent $(V-I)$ relationships were obtained in current clamp by applying a series of current steps $(500 \mathrm{msec},+50$ to $-300 \mathrm{pA})$. In voltage clamp, current-voltage $(I-V)$ relationships were obtained by applying a series of voltage steps $(+24$ to $-36 \mathrm{mV}$ from resting membrane potential). Cell input resistance $\left(R_{\mathrm{N}}\right)$ was calculated from the slope or the inverse of the slope of a least squares regression line fitted to $V-I$ or $I-V$ curves, respectively. Rheobase was estimated by increasing the amplitude of depolarizing square-wave current steps (400-600 msec duration) until a single spike was elicited.

Neurons included in the database satisfied criteria described previously for PMNs (Liu et al., 1990; Dong and Feldman, 1995). Briefly, they had resting membrane potentials of $-60 \mathrm{mV}$ or more hyperpolarized, received rhythmic synaptic drive currents/potentials in phase with inspiratory burst activity on $\mathrm{C} 1$ ventral nerve roots, produced action potentials that overshot $0 \mathrm{mV}$, and were located at intermediate laterality $110-260 \mu \mathrm{m}$ deep from the ventral surface at the level of C4.

Pharmacological substances and application. Drugs that were used included bicuculline methbromide [Research Biochemicals (RBI), Natick, MA; 0.1-1.0 mM], 6-cyano-7-nitroquinoxaline-2,3-dione disodium (CNQX) (RBI; 0.25-0.5 mM), GABA (Sigma, St. Louis, MO; 1 $\mathrm{mM}$ ), hexamethonium bromide (Serva Feinbiochemica, Heidelberg, Germany; 0.1-0.5 mM), 3-[2-methylphenoxy]-1,2-propanediol (mephenesin) (Sigma; $1 \mathrm{~mm}$ ), mecamylamine hydrochloride (RBI; $50 \mu \mathrm{M}),(+)-\mathrm{MK}-$ 801 hydrogen maleate (MK801) (RBI; 0.5-1.0 mM), 5-aminomethyl-3hydroxyisoxazole (muscimol) (Sigma; 10-100 mM), 1,2,3,4-tetrahydro-6nitro-2,3-dioxo-benzo[f]quinoxaline-7-sulfonamide disodium (NBQX) (RBI; 0.375-0.5 mM), strychnine hydrochloride (Sigma; $1 \mathrm{~mm}$ ), and tetrodotoxin (TTX) (RBI; 0.5-1.0 $\mu \mathrm{M})$. All drugs were made up in aCSF and stored as frozen aliquots, with the exception of hexamethonium, which was made fresh before each use.

Drugs were either applied locally over the ventral surface of the $\mathrm{C} 4$ spinal cord over the region containing the PMN pool, or added to the bath. Local application of drugs from triple-barreled pipettes $(6 \mu \mathrm{m}$ per barrel outside diameter at the tip) was via timed pressure injection controlled by solenoid valves.

Drugs were bath-applied when multisegmental action of a given drug was required (e.g., when we wanted to block recurrent inhibition throughout the cervical cord rather than at $\mathrm{C} 4$ alone). The recording chamber was divided into two compartments (split-bath configuration) by construction of a petroleum jelly barrier at the spinomedullary junction. This allowed selective application of drugs to the spinal cord aCSF without affecting processes in the brainstem where respiratory rhythm originates. A minimum of 10 min was allowed for drug equilibration. The split-bath configuration involved analysis of $\mathrm{C} 4$ population output only, because the petroleum jelly used for the partition interferes with formation of $G \Omega$ seals required for whole-cell recording. The integrity of the partition was tested at the start and the end of each experiment by removing all solution from one compartment and verifying that no solution leaked through.

Neuronal properties during inspiratory and expiratory periods: repetitive firing protocol. The paradigm used to compare repetitive firing elicited during inspiration with firing elicited between inspiratory bursts, which we refer to as expiration, is illustrated in Figure 1. First, $\mathrm{C} 1$ ventral root population inspiratory activity and whole-cell recording of PMN inspiratory synaptic inputs were established (see Fig. $1 B i$ ). After inspiratory synaptic inputs were characterized under voltage- and current-clamp conditions, they were blocked via continuous local application of a glutamate receptor antagonist mixture over the C4 PMN pool until no depolarization of PMNs was observed concurrent with inspiratory bursts on the $\mathrm{C} 1$ nerve (see Fig. 1Bii). The antagonist mixture comprised 0.25-0.5 mm CNQX and 0.5 mm MK801, or $0.375 \mathrm{~mm}$ NBQX and 0.5 mM MK801, or 0.5 mm CNQX, $0.375 \mathrm{~mm}$ NBQX, and 0.5 mM MK801. C1 nerve inspiratory activity remained unblocked by the glutamate antagonist cocktail because of its spatial separation from the site of drug injection and therefore was used as an index of cycle phase. The rising phase of C1-integrated inspiratory activity elicited a TTL pulse from a window discriminator that initiated an eight-cycle series of injected current pulse triplets. The first pulse was delivered during inspiration; the second and third pulses of equal magnitude were delivered during the expiratory period (between inspiratory bursts) at 2-4 sec intervals (see Fig. 1Biii). The third pulse was applied to control for the possibility that accommodative properties may have produced different PMN responses to the second of a pair of identical current pulses independent of any phasic alteration of neuron properties. Temporal characteristics of the square-wave pulses were controlled with a Master-8 Stimulator (A.M.P.I., Jerusalem, Israel) and Axodata software. Duration of the pulses was varied from 400 to $600 \mathrm{msec}$ to match the duration of the inspiratory phase of the preparation. Injected current amplitude incremented or decremented with each respiratory cycle (i.e., after one inspiratory and two expiratory pulses), with a total of eight equal steps chosen empirically to produce a range of firing frequencies comparable between PMNs.

Block of primary excitatory inspiratory synaptic drive was essential for these experiments. (1) It prevented changes in motoneuron input conductance associated with activation of the ligand-gated glutamate receptor channels that mediate inspiratory drive (Liu et al., 1990); (2) it removed rapid membrane potential fluctuations associated with inspira- 


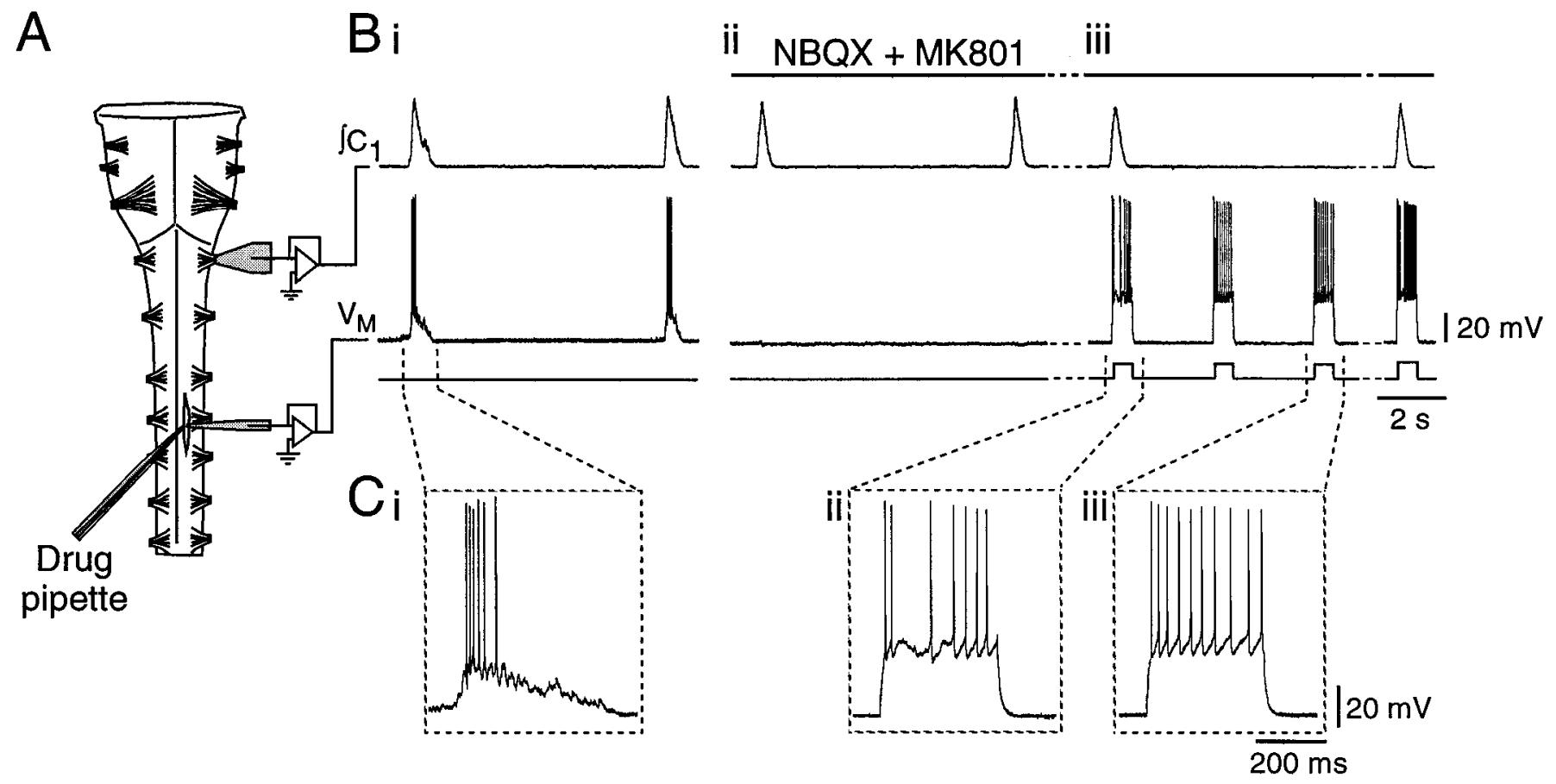

Figure 1. Experimental set-up and protocol for comparison of PMN firing behavior during inspiratory and expiratory phases. $A$, Schematic of the rhythmically active brainstem-spinal cord preparation showing the configuration of the suction electrode for recording first cervical nerve (C1) activity, the whole-cell recording electrode at the level of the fourth cervical nerve for recording PMN activity, and the triple-barrel drug ejection pipette. $B$, Rectified, integrated recording of $\mathrm{C} 1$ output $\left(\int C_{1}\right.$, top trace) showing population inspiratory activity and whole-cell current-clamp record of a PMN ( $V_{M}$, middle trace) $(i)$ under control conditions with inspiratory synaptic potential present, (ii) after complete blockade of the PMN excitatory inspiratory input with NBQX and MK801, and (iii) during the repetitive firing protocol in the continued presence of NBQX and MK801. After block of excitatory inspiratory drive to the PMN (Bii), population inspiratory activity on $\int \mathrm{C}_{1}$ was used to trigger injection of square-wave current pulses during inspiration (Biii). Responses of PMNs to current pulses injected during inspiratory and expiratory periods were then compared. $C$, Expanded versions of voltage traces $\left(V_{\mathrm{M}}\right)$ in $B$, showing the firing responses of the PMN to $(i)$ endogenous inspiratory synaptic input, $(i i)$ a 380 pA pulse delivered during inspiration, and (iii) the same amplitude current pulse delivered during expiration.

tory synaptic drive (see Fig. $1 \mathrm{Bi}$ ), facilitating analysis of repetitive firing behavior; and most importantly, (3) it ensured that inspiratory-phase responses were not evoked from more depolarized membrane potentials than expiratory-phase responses. If excitatory synaptic inputs were not blocked, inspiratory-phase responses would be from the summed action of synaptic and injected currents, whereas expiratory-phase responses would represent responses to injected current only. Thus PMNs were not subjected to the repetitive firing protocol if inspiratory-phase depolarizations were still observed.

Tests for phase-dependent changes in $\mathrm{R}_{N}$. PMN $R_{\mathrm{N}}$ during inspiratory and expiratory periods was compared, after block of glutamatergic inputs, from the slope of least squares regression line fitted through voltage-current relationships generated by plotting the steady-state voltage responses to incrementing or decrementing current pulses $(50 \mathrm{pA}$ steps; -200 to $+50 \mathrm{pA}$ ) delivered during the inspiratory and expiratory periods. As above, the rising phase of $\mathrm{C} 1$ inspiratory activity was used as the index of inspiratory onset.

Data acquisition and analysis. Signals were displayed on line on a chart recorder and oscilloscope and were recorded on videotape via pulse code modulation (Vetter 402 or 3000A; A. R. Vetter, Rebersberg, PA) (sampled at $10-40 \mathrm{kHz} /$ channel) for storage and off-line analysis. Selected portions of data were digitized at $1-20 \mathrm{kHz}$ using AxoData software and a National Instruments NBMIO-16 A/D board and stored on computer for subsequent analysis. Peaks of EPSPs and IPSPs and of integrated nerve activity were calculated using the peak detection analysis in AxoGraph software (version 3.0). The effects of bath-applied and locally applied drugs on frequency and peak amplitude of $\mathrm{C} 4$ inspiratory bursts were assessed using a custom-written LabV IEW acquisition and analysis program.

PMNs exhibited a wide range of rheobase, $R_{\mathrm{N}}$, and maximum firing frequency values. Thus, the absolute magnitude of the eight current pulses injected to examine repetitive firing varied between PMNs. Therefore to pool data on firing frequency versus injected current from different PMNs for statistical analysis, firing frequency was plotted against the current step number rather than absolute current. Each of the eight steps produced a similar increment in PMN output relative to maximum firing for that cell.

Data are reported as mean \pm SE. Means of data on $\mathrm{C} 4$ burst amplitude and PMN subthreshold properties were compared using a two-tailed Student's paired $t$ test. An arc sine transform was performed to normalize all percentage data before statistical comparison. Comparison of PMN firing behavior during the inspiratory and expiratory phase was made with Statistical Analysis Software using an $8 \times 3$ or $3 \times 3$ univariate one-way ANOVA for unbalanced data sets. Linear contrast coefficients were used to partition the sum of squares to determine whether firing was significantly different between inspiration and expiration or between the two expiratory pulses. Values of $p<0.05$ were assumed to be significant.

\section{RESULTS}

Behavior of brainstem-spinal cord preparations isolated from P0-P3 Wistar rats was indistinguishable from that of similar preparations isolated from Sprague Dawley rats [Smith and Feldman (1987); Lin et al. (1990); Dong and Feldman (1995); also see Connelly et al. (1992)]. Preparations produced spontaneous inspiratory-related bursts of activity $(5-12 / \mathrm{min})$ on ventral cervical nerve roots. Burst envelopes were rapidly incrementing and slowly decrementing (Fig. 1).

PMN properties were also similar to those described previously (Liu et al., 1990; Dong and Feldman, 1995). PMNs received rhythmic synaptic input (200-1500 pA) in phase with C1 inspiratory nerve activity, had resting membrane potentials of $-64 \pm 1$ $\mathrm{mV}, R_{\mathrm{N}}$ of $79 \pm 5 \mathrm{M} \Omega$ in control solution $(n=41)$, and fired 
A INSPIRATION
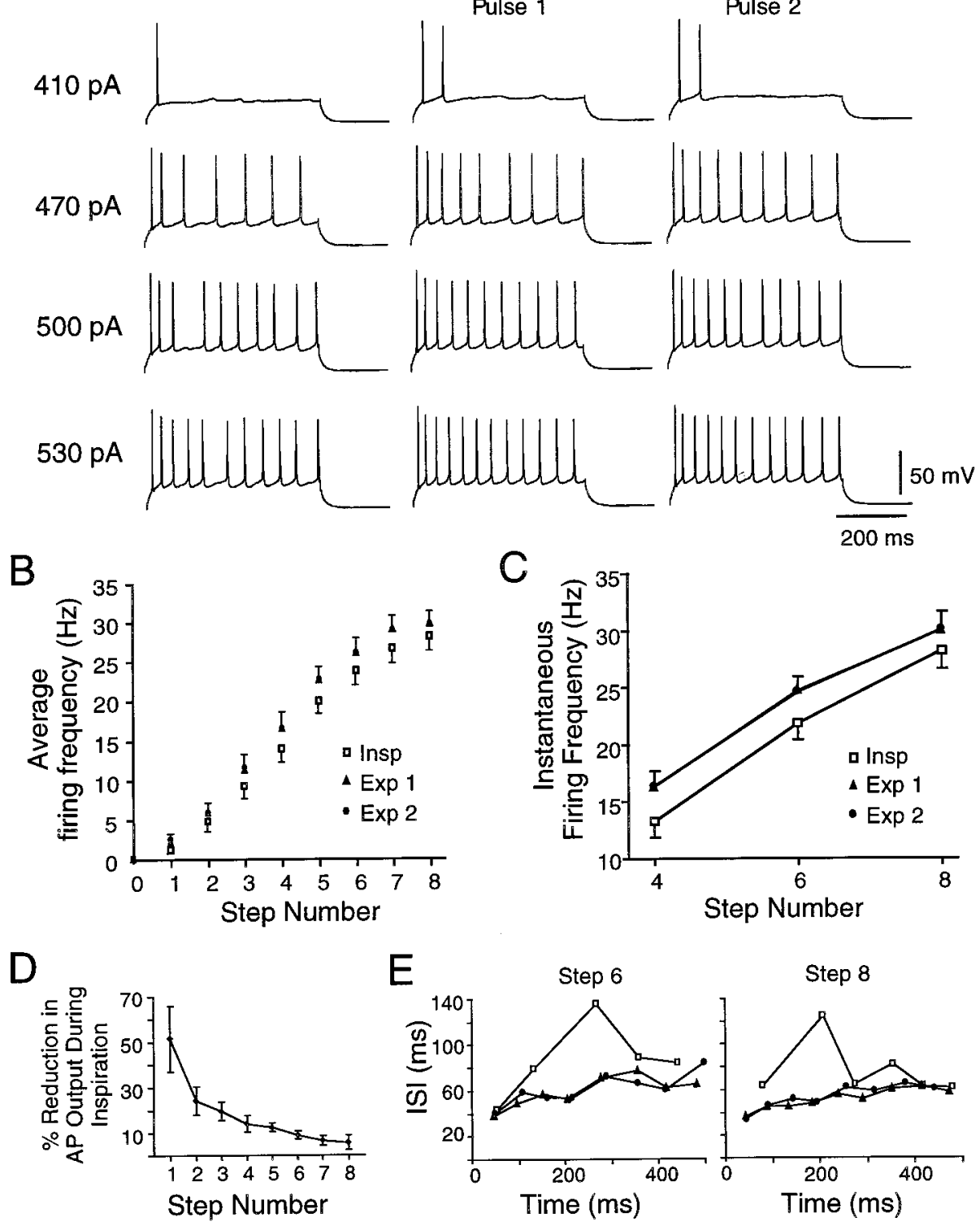

Figure 2. PMN excitability is reduced in inspiration relative to expiration. $A$, Responses of one PMN to four levels of current steps presented during inspiration and at two times during expiration after block of excitatory inspiratory synaptic input. Responses to pulses presented during the inspiratory phase are shown in the left-hand traces (INSPIRATION); responses to pulses presented during the expiratory phase are shown in the middle (EXPIRATION, Pulse 1) and right-hand traces (EXPIRATION, Pulse 2). Pulse amplitude is indicated to the left of each triplet. $B$, Plot of total pulse firing frequency versus current step number calculated from responses to pulses presented during inspiration (Insp) and at two times during expiration $(\operatorname{Exp} 1, \operatorname{Exp} 2)(n=$ 14). $C$, Plot of instantaneous firing frequency versus current step number calculated from responses to the fourth, sixth, and eighth current steps during inspiration (Insp) and at two times during expiration $(\operatorname{Exp} 1, \operatorname{Exp} 2)(n=$ 14). $D$, Plot of percentage reduction in inspiratory-phase action potential $(A P)$ output (number of APs relative to expiratory phase discharge) as a function of current step number. $E$, Plots of interspike interval (ISI) duration versus interval number for repetitive firing in one PMN. Firing was elicited by the sixth (left-hand trace) and eighth (right-hand trace) current steps delivered during inspiration $(\square)$ and by the same current levels at two times during the expiratory phase $(\operatorname{Exp} 1, \mathbf{\Delta}$; Exp 2, ). Compare with Figure $4 C$. repetitively in response to square-wave depolarizing current pulses (rheobase, $370 \pm 210 \mathrm{pA}$ ).

\section{Repetitive firing is reduced during inspiration versus expiration}

To facilitate comparison of repetitive firing behavior of PMNs during inspiration and expiration, excitatory synaptic inputs mediating the inspiratory drive were blocked with local application of NBQX or CNQX + MK801 or both. Drugs were applied continuously to ensure continued block of excitatory synaptic drive until protocols were completed. Although $95 \%$ of the inspiratory synaptic inputs to PMNs can be blocked by 5-50 $\mu \mathrm{M}$ CNQX (Liu et al., 1990), complete block of excitatory input required up to $500 \mu \mathrm{M} C \mathrm{CNX}$ or NBQX. MK-801 was included in the antagonist solution to ensure that all ionotropic glutamatergic receptors were blocked (Greer et al., 1991). Complete block of excitatory drive was determined by the absence of inspiratory-phase depolarizing inputs to the recorded PMN. Although recent observations suggest a possible metabotropic glu- tamate receptor contribution to the inspiratory drive to PMNs (Dong and Feldman, 1996), our ability to completely block inspiratory-phase depolarization in 32 of 37 PMNs suggests that a metabotropic component is not present in all cells, or that, where present, it was blocked by the high concentrations of antagonists. Complete block typically took 5-15 min. The antagonist mixture was associated with a $22 \pm 4 \%$ increase in $R_{\mathrm{N}}$ (to $97 \pm 6 \mathrm{M} \Omega ; n=26)$.

The repetitive firing protocol was completed in 20 of the PMNs in which all inspiratory-phase depolarization was blocked. Visual inspection of the responses revealed a clear reduction in inspiratory-phase firing in 14 PMNs, as shown for one PMN in Figure $2 A$. In the remaining six PMNs, differences between inspiratory and expiratory firing responses were not obvious. We compared firing frequencies between inspiration and expiration on data pooled from all 20 PMNs and on data from the 14 cells showing obvious reductions in inspiratory-phase firing. Inspiratory-phase firing was significantly lower than expiratory 
firing regardless of whether 20 or 14 cells were used for analysis (see below). Because the 14 PMNs with obvious phase differences in firing may represent a subpopulation of PMNs that receive inspiratory modulation, we report only the quantitative results from analysis of those cells. Firing frequencies were calculated in two ways. (1) To quantify the overall response to a current pulse, the number of action potentials produced was divided by pulse duration. This gave a value for average firing frequency that enabled comparison of firing between inspiration and expiration at current levels that did not produce enough action potentials to calculate a representative instantaneous firing frequency. (2) Instantaneous firing frequency, the inverse of the interspike interval duration, was also averaged at the fourth, sixth, and eighth current steps to ensure that average and instantaneous firing frequencies responded similarly to inspiratory and expiratory input.

The relationship of firing frequency to injected current step was shifted to the right during inspiration (i.e., more current was needed to produce a given firing frequency). Thus the overall mean spike frequency during inspiration $(15.4 \pm 1.1 \mathrm{~Hz})$ was significantly lower than during expiration $(17.4 \pm 1.1 \mathrm{~Hz} ; n=14$; $p<0.001$ ) (Fig. 2B). Similarly, instantaneous firing frequency was significantly lower during inspiration than during expiration. At the fourth, sixth, and eighth steps, average instantaneous firing frequencies during inspiration were $13 \pm 1,22 \pm 1$, and $28 \pm 2$ $\mathrm{Hz}$, respectively, versus $16 \pm 1,25 \pm 1$, and $30 \pm 2 \mathrm{~Hz}$ during expiration $(p<0.001)$ (Fig. $2 C$ ). Firing frequency responses to pulses delivered early and late in expiration were not different at any level of current $(p>0.5)$ regardless of whether average or instantaneous firing frequencies were compared (Fig. 2B,C). The reduction in firing was manifest as one or two fewer action potentials per $400-600 \mathrm{msec}$ current pulse, independent of current level. Thus, when expressed in terms of relative change in action potential output, the reduction in inspiratory versus expiratory discharge was greater at the lower firing levels (Fig. 2D). Relative to the expiratory phase, inspiratory firing was reduced by $49 \pm 15 \%$ and $7 \pm 3 \%$ for steps 1 and 8 , respectively $(n=14)$.

Plots of interspike interval duration against time, calculated from the firing responses to square-wave pulses, revealed that interspike interval durations increased during inspiration relative to expiration (Fig. 2E), indicating that excitability is reduced during the inspiratory phase.

\section{The reduction in inspiratory firing is caused by phasic inspiratory inhibition}

The increase in duration of interspike intervals during evoked repetitive firing in the inspiratory phase indicated that PMN excitability was decreased during inspiration. Examination of membrane potential during the inspiratory phase (after block of excitatory synaptic input) revealed that in 16 of the 32 PMNs in which the inspiratory-phase depolarization was completely blocked, a small hyperpolarizing input arrived coincident with inspiratory bursts on the $\mathrm{C} 1$ nerve. Ten of the PMNs exhibiting this hyperpolarization were among those subjected to the repetitive firing protocol. Of these $10 \mathrm{PMNs}$, nine showed a clear reduction in inspiratory firing. Failure to observe a hyperpolarization in $\sim 50 \%$ of the PMNs may reflect that not all PMNs are phasically inhibited or that where unobserved, the hyperpolarization was masked by incompletely blocked excitatory drive. The latter possibility was supported by the finding that blocking the hyperpolarization with bicuculline (100-200 $\mu \mathrm{M})$ in 10 cells revealed a small $(<2 \mathrm{mV})$ remaining inspiratory-phase depolarization in four of them (data not shown).
A
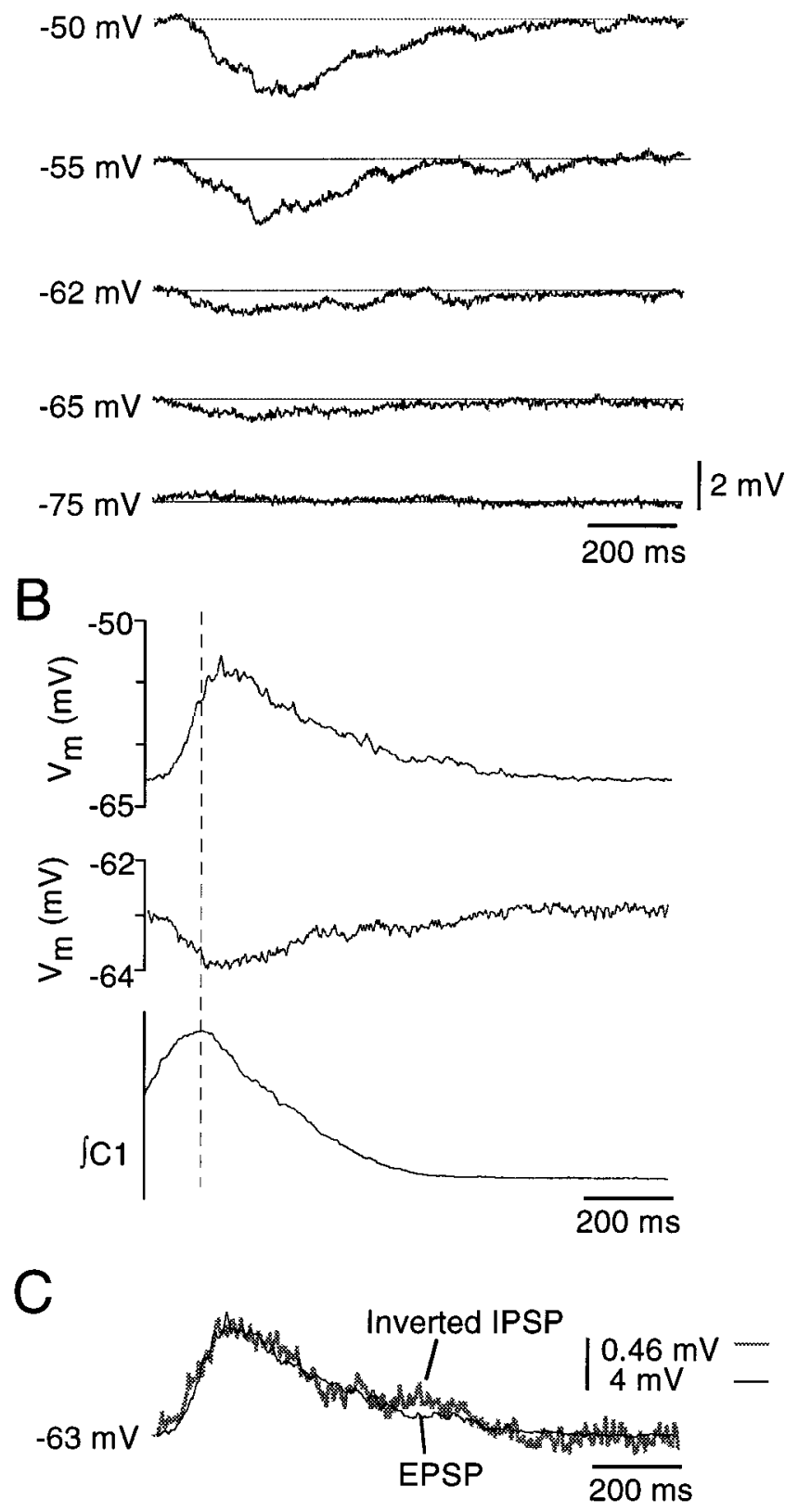

Figure 3. PMNs receive hyperpolarizing input during inspiration. $A$, Current-clamp recordings from one PMN illustrating the magnitude of the inspiratory hyperpolarization at five different membrane potentials (shown at left of traces). Traces represent averages of five inspiratory cycles. $B$, Time course of the excitatory (top trace) and inhibitory inspiratory potentials (middle trace) relative to the inspiratory burst recorded from $\mathrm{C} 1$ (bottom trace). Traces represent averages of 10 inspiratory cycles. $C$, The high degree of overlap between these inspiratory excitatory and inhibitory synaptic inputs is demonstrated by inverting and amplifying (8.7 times) the inhibitory input (gray trace) and superimposing it on the excitatory input (thin black trace).

An example of the inspiratory hyperpolarization in one PMN in current clamp is shown in Figure $3 A$. Hyperpolarizations had an average duration of $580 \pm 97 \mathrm{msec}$ at a membrane potential of $-55 \mathrm{mV}$. Peak magnitude was dependent on membrane potential, increasing from $-0.7 \pm 0.1 \mathrm{mV}$ at resting membrane potential $(-62 \mathrm{mV})$, to $-1.1 \pm 0.4 \mathrm{mV}$ and $-1.5 \pm 0.5 \mathrm{mV}$ at -55 and -50 
$\mathrm{mV}$, respectively $(n=4)$. The hyperpolarization reversed between -65 and $-75 \mathrm{mV}$ (Fig. $3 A$ ).

Durations of the inhibitory $(580 \pm 97 \mathrm{msec})$ and excitatory $(690 \pm 66 \mathrm{msec})$ inputs to PMNs were similar $(n=6)$, and a rapidly incrementing, slowly decrementing envelope was common to both. The temporal relationship between excitatory and inhibitory inspiratory synaptic inputs could not be established directly because the inhibitory input was only visible during block of the excitatory input. Instead, the timing of the peak of the excitation, measured before application of glutamate antagonists, and the peak of the inspiratory inhibition, measured after glutamate receptor block, were compared relative to the peak of the $\mathrm{C} 1$ ventral root inspiratory burst. Peaks of the inspiratory synaptic excitation and inhibition were thus determined to be nearly coincident, arriving $10 \pm 10 \mathrm{msec}$ and $34 \pm 22 \mathrm{msec}(n=5)$, respectively, after the peak of the $\mathrm{C} 1$ nerve inspiratory burst (Fig. 3B).

Not only was its time course similar: the inspiratory inhibition corresponded closely in shape to the inverted excitatory drive. This is shown for one PMN in Figure $3 C$ where the inhibitory potential envelope averaged from 10 inspiratory cycles was inverted, scaled (in this case amplified 8.7 times), and superimposed on the averaged excitatory inspiratory input (before it was blocked) from the same cell. The close correspondence of the relationships between inhibitory and excitatory synaptic inputs (Fig. 3C) is consistent with the possibility that inhibitory and excitatory drives are proportional.

To test whether the inspiratory hyperpolarization was mediated via GABA receptors, we examined the effects of locally applied bicuculline $\left(\mathrm{GABA}_{\mathrm{A}}\right.$ receptor antagonist; 100-200 $\left.\mu \mathrm{M}\right)$ on the inspiratory-related hyperpolarization. Bicuculline blocked the hyperpolarization in all PMNs tested $(n=11)$ (Fig. $4 A)$. It also eliminated the difference between inspiratory and expiratory firing (Fig. 4B) $(n=3)$ and blocked the differences between inspiratory and expiratory firing behavior evident in the plots of interspike interval versus time (Fig. 4C). These data support our hypothesis that the inspiratory-phase hyperpolarization was responsible for reduced firing during the inspiratory relative to the expiratory phase.

\section{GABA receptor activation inhibits PMN excitability}

We tested the effects of GABA and muscimol $\left(\mathrm{GABA}_{\mathrm{A}}\right.$ receptor agonist) on PMN properties and repetitive firing behavior to determine whether their actions supported our hypothesis that the reductions in inspiratory firing were caused by endogenous activation of $\mathrm{GABA}_{\mathrm{A}}$ receptors.

GABA (1 mM, applied locally) rapidly (within one inspiratory cycle) and reversibly reduced the number of spikes produced during the inspiratory phase (Fig. 5A), completely blocking inspiratory-phase firing in six of six cells. Similarly, GABA greatly reduced repetitive firing elicited by current injection $(n=$ 6) (Fig. 5B). This was not due to block of cells' ability to fire action potentials, because higher amplitude current pulses still elicited repetitive firing (data not shown). The associated increase in rheobase did not appear to be attributable to a change in spike threshold but to a reduction in cell $R_{\mathrm{N}}$ by GABA to $33 \pm 8 \%$ of control $(n=10)$ (Fig. 5C,D). The GABA-induced decrease in $R_{\mathrm{N}}$ persisted in TTX $(n=3)$ (Fig. $5 D)$, suggesting that it is mediated at least in part by postsynaptic receptors. The effects of GABA were mimicked by the $\mathrm{GABA}_{\mathrm{A}}$ receptor agonist muscimol (0.01$1.0 \mathrm{mM})$, which similarly decreased $R_{\mathrm{N}}$ to $48 \pm 12 \%$ of control $(n=4)$ (Fig. $5 C)$. No consistent effects on membrane potential

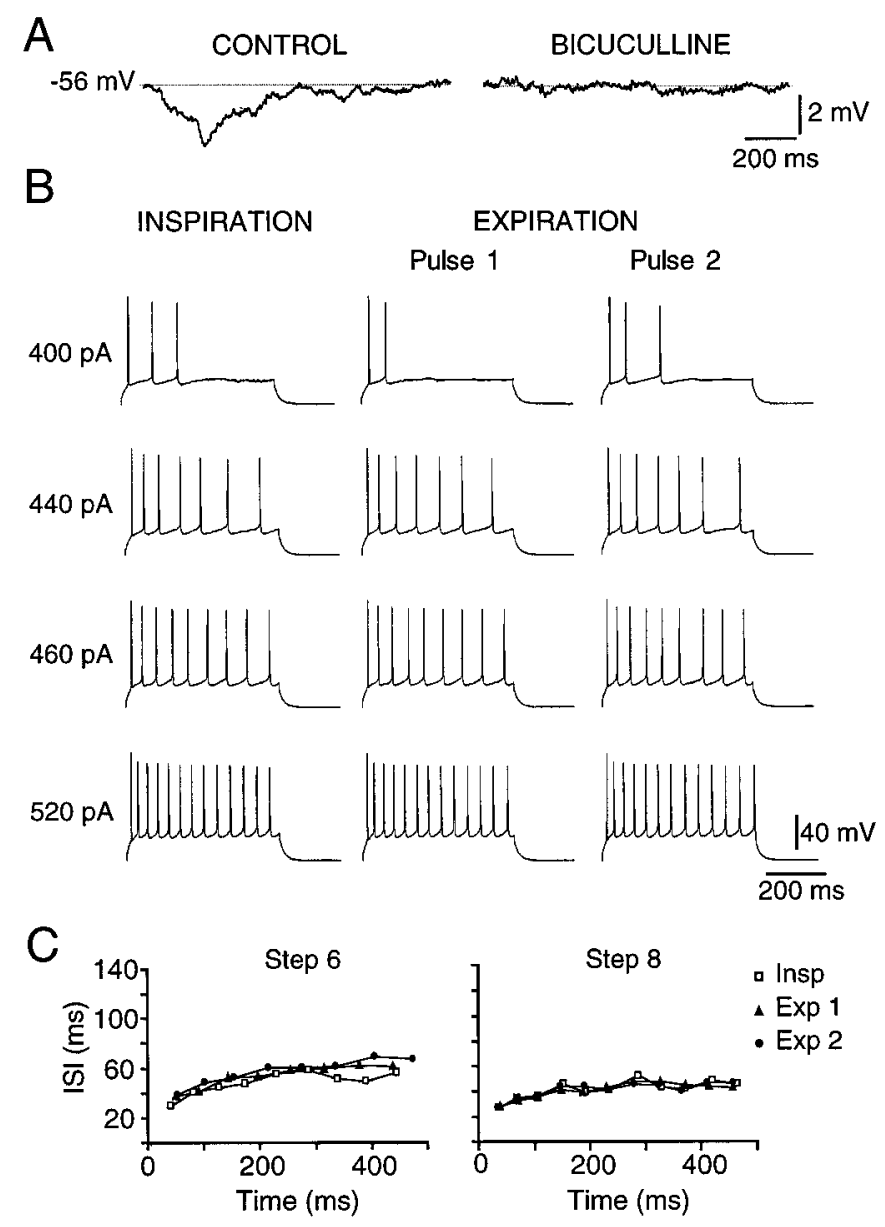

Figure 4. The hyperpolarizing inspiratory inhibition of PMNs and the reduction in PMN firing during inspiration are blocked by bicuculline. $A$, The same cell as in Figure $3 A$ at $-56 \mathrm{mV}$. The membrane potential of a PMN during the inspiratory phase, before (CONTROL) and after local application of $200 \mu \mathrm{M}$ bicuculline (BICUCULLINE). Traces are averages of eight inspiratory cycles. $B$, Bicuculline $(200 \mu \mathrm{M})$ blocked the reduction in spike output during inspiration relative to expiration (same cell as in Fig. 2A). C, Bicuculline also blocked the increases in inspiratory interspike interval (same cell and current steps as in Fig. 2E).

were observed in response to GABA or muscimol at resting membrane potential $(-63 \pm 5 \mathrm{mV})$.

In keeping with its observed effects on PMN activity, local application of $1 \mathrm{~mm}$ GABA over the $\mathrm{C} 4$ spinal cord for 10,30 , and $60 \mathrm{sec}$ significantly reduced $\mathrm{C} 4$ nerve burst amplitude to $40 \pm 7$, $25 \pm 7$, and $21 \pm 7 \%$ of control (Fig. 6) $(n=5)$.

\section{Bicuculline potentiates C4 inspiratory activity}

To assess the impact of the bicuculline-sensitive inspiratory inhibition of PMNs on inspiratory input to the diaphragm, we measured changes in $\mathrm{C} 4$ nerve burst activity after locally applying bicuculline (1 mM) over the $\mathrm{C} 4 \mathrm{PMN}$ pool. Bicuculline (1 mM; $30-60 \mathrm{sec}$ ) significantly increased $\mathrm{C} 4$ nerve burst amplitude by $33 \pm 9 \%$ (Fig. 6) $(n=14 ; p<0.05)$. The bicuculline-induced potentiation peaked at $1-2 \mathrm{~min}$ and returned to control levels 10-15 min after application.

A bicuculline-induced potentiation of $\mathrm{C} 4$ burst amplitude could result from block of tonic rather than inspiratory-phase GABAmediated inhibition of PMN activity. We therefore examined the effects of bicuculline on PMN membrane properties and repeti- 
A

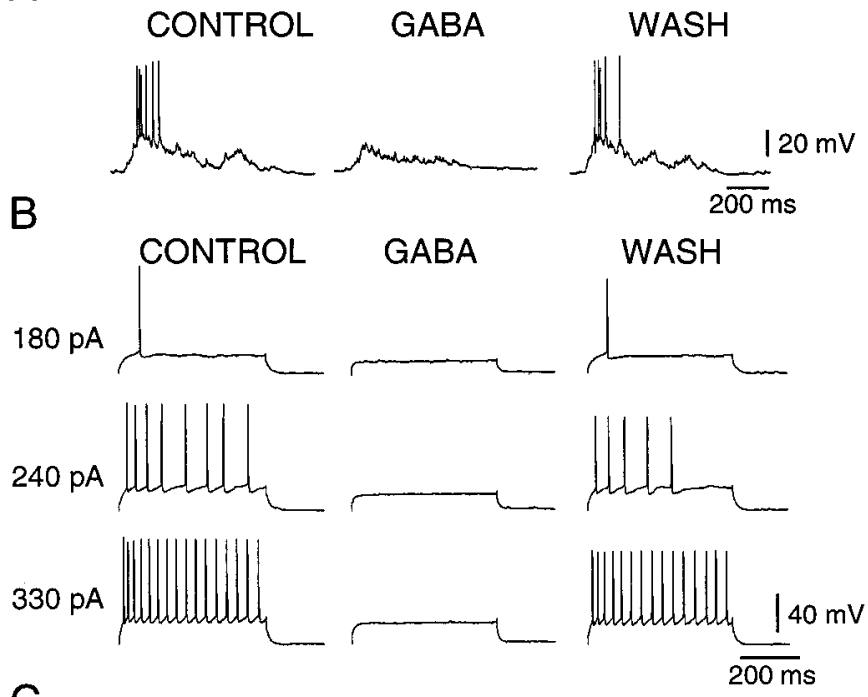

C

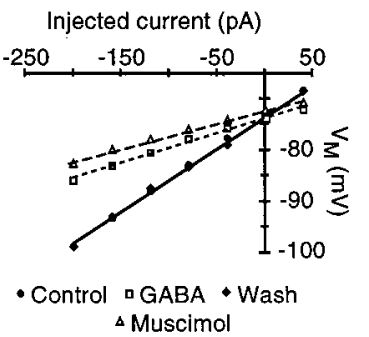

D

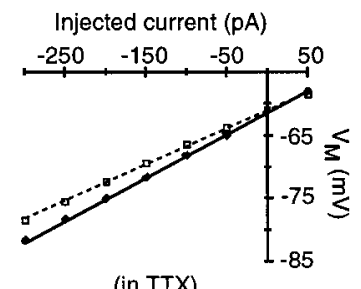

(in TTX)

- Control a GABA - Wash

Figure 5. GABA reduces PMN excitability. $A$, Current-clamp recording from a PMN before (CONTROL), during $(G A B A)$, and after $(W A S H)$ local application of GABA $(1 \mathrm{~mm})$ over the $\mathrm{C} 4$ phrenic motoneuron pool. During GABA application, endogenous excitatory synaptic drive did not elicit action potentials. $B$, The same PMN as in $A$, showing that injected current pulses that elicited firing in control did not bring the cell to threshold during GABA application. $C$, Plot of membrane potential versus injected current for one PMN, showing a decrease in slope of the $V-I$ relationship in the presence of GABA $(1 \mathrm{~mm}, \square)$ or muscimol $(0.01$ $\mathrm{mM}, \triangle$ ) relative to control $(\bullet)$, indicating a reduction in cell $R_{\mathrm{N}} . D$, Application of GABA (1 mM) also reduced $R_{\mathrm{N}}$ after block of synaptic transmission with $0.8 \mu \mathrm{M}$ TTX (different cell than in $C$ ).

tive firing behavior during expiration. Consistent with a phasedependent (inspiratory) inhibition, bicuculline $(0.2$ or $1.0 \mathrm{~mm}) \mathrm{did}$ not increase $R_{\mathrm{N}}$ during the expiration $(n=9)$ (Fig. $7 C$ ), nor did it alter the relationship between injected current and firing frequency $(n=4)$ (Fig. $7 D, E)$. Establishing that the potentiation of C4 burst amplitude by bicuculline results from block of an inspiratory-phase inhibition enabled us to later use bicucullineinduced potentiation as an indirect measure of the magnitude of the inspiratory inhibition (Figs. 7, 9, 10).

\section{GABA-mediated gain modulation of PMN excitability}

The shapes of IPSPs and EPSPs appear similar (Fig. 3). This raises the possibility that the GABA-mediated inhibition provides a means for gain control over PMN output. Gain control is defined as a process whereby the output discharge frequency of a neuron, $F_{\mathrm{o}}(t)$, is the product of its discharge frequency in the absence of modulation, $F_{\mathrm{i}}(t)$, and a modulation coefficient $(1-\alpha)$ (McCrimmon et al., 1997). If endogenous GABAergic inhibition decreases gain of the PMN to inspiratory inputs, it would reduce the peak output of the PMN, reduce the slope of the relation between $F_{\mathrm{o}}(t)$ and $F_{\mathrm{i}}(t)$ below identity, and cause minimal change
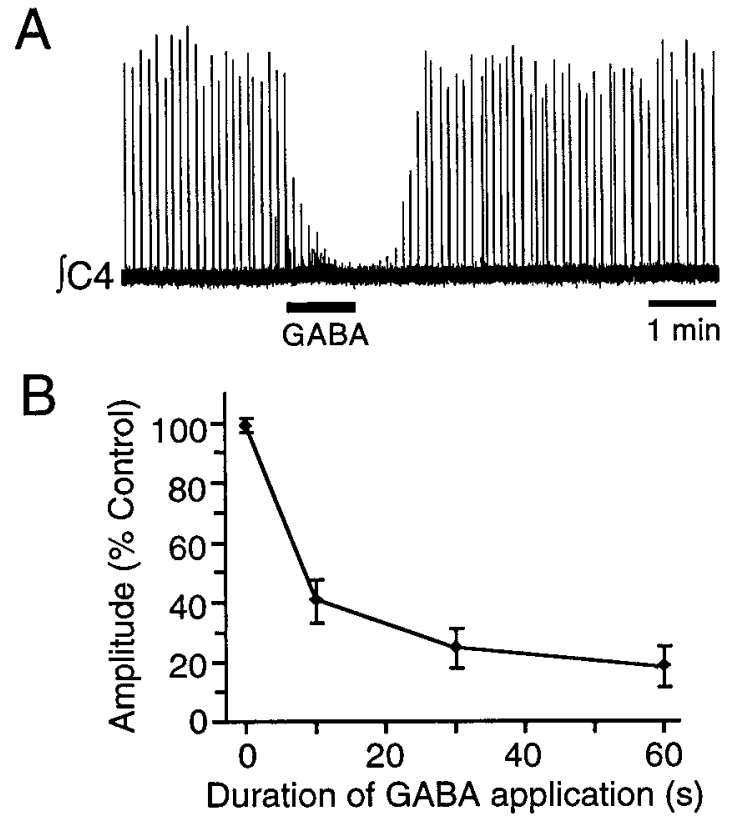

Figure 6. A, Sixty second application of GABA (1 mM) over the PMN pool nearly abolished $\int C 4$ population inspiratory activity in a $\mathrm{P} 1$ rat. $B$, Pooled data showing the dose-dependent reduction in $\int \mathrm{C} 4$ burst amplitude (expressed as percentage of control amplitude) produced by 10, 30 , and $60 \mathrm{sec}$ applications of $1 \mathrm{~mm}$ GABA over the C4 motoneuron pool $(n=5$; mean $\pm \mathrm{SE})$.

in burst duration, such that $F_{\mathrm{o}}(t)=(1-\alpha) F_{\mathrm{i}}(t)$. Blocking this inhibition would have the opposite effect.

To test for gain modulation, we examined the effect of bicuculline applied over the PMN pool on $\mathrm{C} 4$ nerve inspiratory bursts. We examined $\mathrm{C} 4$ output rather than individual PMN output because (1) $\mathrm{C} 4$ output provides a reliable estimate of PMN activity, as evident in the close correspondence between the shape of the inspiratory synaptic drive potential and $\mathrm{C} 4$ burst envelope (Fig. 8), and (2) firing of individual PMNs during inspiration was often low, making it difficult to establish a reliable relationship between discharge $F_{\mathrm{o}}(t)$ and $F_{\mathrm{i}}(t)$. Thus, we compared voltage of the integrated $\mathrm{C} 4$ nerve recording during bicuculline $\left(V_{\text {(bic) }}\right)$ versus control $\left(V_{(\text {con })}\right)$. Voltage was measured at $25 \mathrm{msec}$ intervals during the decrementing phase of the cycle (Fig. $8 A$, boxed region). Figure $8 A$ shows the voltage profile of the integrated $\mathrm{C} 4$ nerve burst (averaged from 10 cycles) for one preparation before and after bicuculline application. Bicuculline increased the peak C4 burst amplitude (also apparent in Fig. 7). Linear regression indicated that the slope of the relationship between $V_{\text {(bic) }}$ and $V_{\text {(con) }}$ was greater than unity (control) (Fig. $8 B$ ). The slope and intercept were $1.47 \pm 0.10$ and $0.20 \pm 0.04$, respectively $(n=3)$. Burst duration was not significantly affected by bicuculline $(673 \pm 72 \mathrm{msec}$ in control; $714 \pm 113 \mathrm{msec}$ in bicuculline). These data suggest that phasic GABAergic input modulates PMN gain during inspiration. Although this may appear inconsistent with the lack of a change in slope in the relationship between firing and injected current step in Figure $2 B$, a change in slope would not be expected in that relationship because the square-wave pulses used to elicit the firing did not match the waveform of the inspiratory inhibition. The proposed gain control arises from the proportionality of the excitatory and inhibitory inputs. 
Figure 7. Bicuculline increases C4 inspiratory output without changing $R_{\mathrm{N}}$ or firing responsiveness of PMNs during expiration. $A$, Rectified, integrated $\mathrm{C} 4$ nerve recording from a $\mathrm{P} 1$ rat showing increased burst amplitude in response to a $60 \mathrm{sec}$ application of bicuculline (1 mM) over the PMN pool (bar under trace). B, Time course of the effects of bicuculline on $\mathrm{C} 4$ inspiratory burst amplitude expressed as a percentage of control $(n=5$; mean $\pm \mathrm{SE})$. $C$, Bicuculline $(0.2-1.0$ $\mathrm{mM}$ ) had no significant effect on $R_{\mathrm{N}}$ of PMNs measured during expiration $(n=10) . D$, Current-clamp recording from a PMN showing repetitive firing during expiration elicited by current steps injected under control conditions and during local application of bicuculline $(1 \mathrm{mM})$ over the $\mathrm{C} 4$ motoneuron pool. $E$, Plot of firing frequency versus injected current during expiration for a PMN in control (๑) and bicuculline (1 mM, $\square)$.
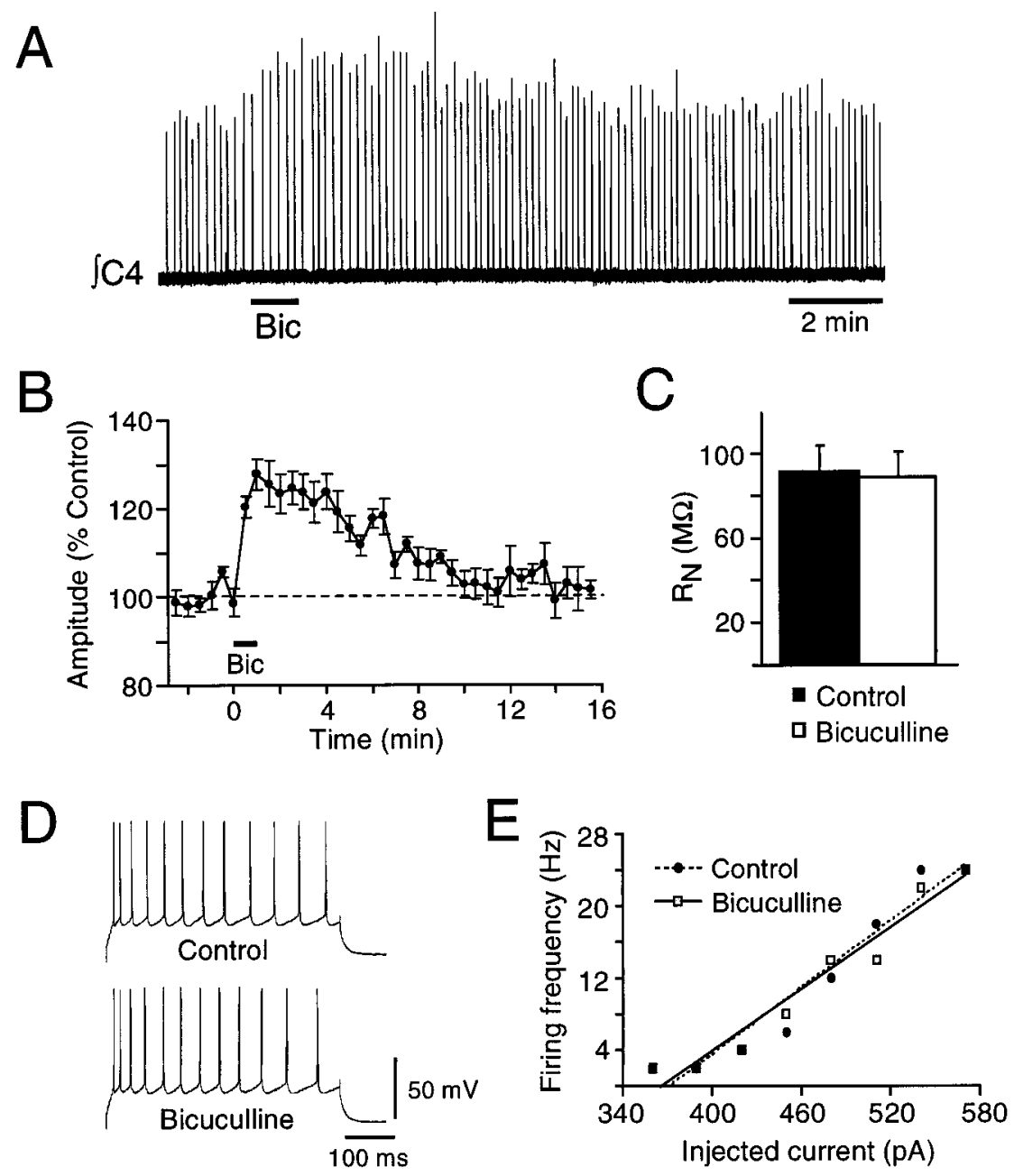

\section{Source of inspiratory inhibition}

The endogenous GABA-mediated inspiratory inhibition to PMNs had two potential sources: (1) recurrent (feedback) inhibition arising from PMN activation of Renshaw cells or (2) concurrent (feedforward) inhibition from the brainstem via either direct monosynaptic inhibition of PMNs from bulbospinal inspiratory inhibitory neurons, or polysynaptic inhibition through activation of GABAergic interneurons in the spinal cord by bulbospinal inspiratory excitatory neurons.

\section{Recurrent Inhibition}

Recurrent inhibition sometimes has a GABAergic component (Curtis et al., 1976; Cullheim and Kellerth, 1981; Schneider and Fyffe, 1992); however, there are no reports of recurrent inhibition in which glycine does not play a major role. Thus, if recurrent inhibition were the source of the inspiratory hyperpolarization, block of glycine receptors should potentiate $\mathrm{C} 4$ inspiratory burst amplitude. Strychnine (1 mM), a glycinergic antagonist, had no significant effect on $\mathrm{C} 4$ output when applied for up to $2 \mathrm{~min}(n=$ 6) (Fig. $9 A, B$ ) over the $\mathrm{C} 4$ motoneuron pool at the same site where GABA inhibited (Fig. 6), and bicuculline potentiated (Fig. $7 A, B), C 4$ inspiratory burst amplitude.

Motoneuronal excitation of Renshaw cells, which mediate recurrent inhibition, is largely via nicotinic acetylcholine receptors (nAChRs) (Curtis and Ryall, 1966; Noga et al., 1987). Thus, we used the split-bath configuration to further test for involvement of recurrent inhibitory pathways in producing the inspiratory inhibition. The nAChR antagonists hexamethonium and mecamylamine were applied in the spinal bath to determine whether they would increase $\mathrm{C} 4$ inspiratory burst amplitude and occlude the bicuculline-mediated response. Hexamethonium (500 $\mu \mathrm{M})$ had no effect on C4 burst amplitude, nor did it block potentiation of $\mathrm{C} 4$ nerve burst amplitude induced by locally applied bicuculline ( $1 \mathrm{mM})(n=2$; data not shown). Similarly, C4 burst amplitude was unaffected by application of mecamylamine $(50 \mu \mathrm{M})$ to the spinal cord bath. The bicuculline-mediated potentiation of C4 burst amplitude was reduced slightly in mecamylamine, from $42 \pm 5$ to $35 \pm 4 \%(n=5)$, but was never abolished (Fig. $9 C$ ).

\section{Feedforward inhibition from inspiratory-modulated brainstem areas}

The minimal change in the $\mathrm{C} 4$ inspiratory output after disruption of recurrent inhibitory spinal networks suggested that the inspiratory inhibition originates supraspinally. To test whether the inspiratory inhibition of PMN activity was monosynaptic or polysynaptic (see above), mephenesin was applied to the solution perfusing the spinal cord (split-bath configuration) to selectively block transmission in polysynaptic versus monosynaptic pathways within the spinal cord (Farkas et al., 1989). Mephenesin (1 mM) reduced $\mathrm{C} 4$ output by $30-40 \%$ but did not alter the bicucullinemediated increase in C4 burst amplitude $(n=4)$, which was $28 \pm$ $3 \%$ in control and $29 \pm 3 \%$ in mephenesin (Fig. 9D). 

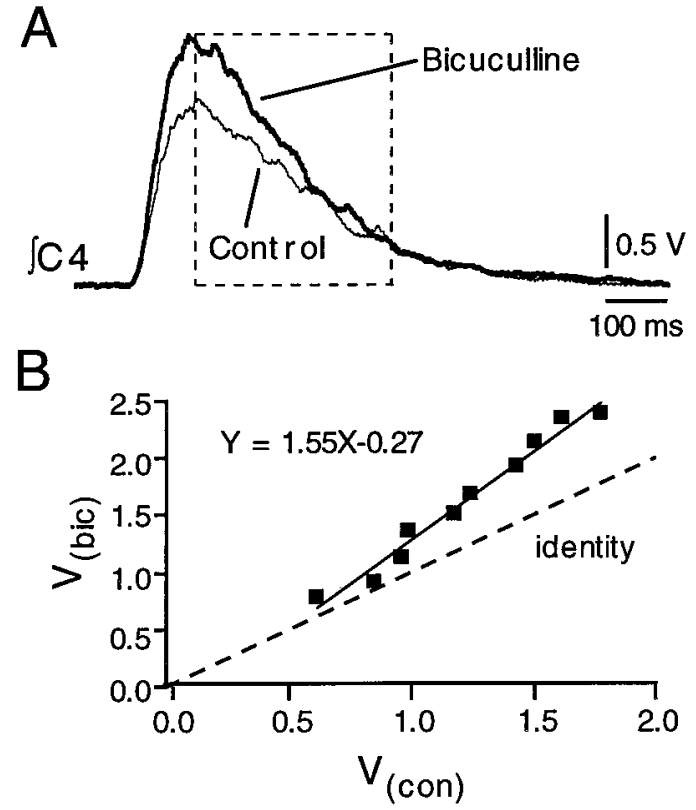

Figure 8. GABA-mediated gain modulation of PMN inspiratory activity. $A$, Superimposed voltage profiles of the integrated $\mathrm{C} 4$ nerve inspiratory burst envelopes (averaged from 10 cycles) for one preparation before (Control) and after local application of bicuculline $(1 \mathrm{mM})$ over the $\mathrm{C} 4$ PMN pool. Bicuculline increased $\mathrm{C} 4$ burst amplitude and the slope of $\mathrm{dV} / \mathrm{dt}$, but did not change burst duration. $B$, Measurements of voltage, taken at $25 \mathrm{msec}$ intervals through the decrementing phase (region enclosed in box) of the control and bicuculline $\mathrm{C} 4$ burst envelopes shown in $A$ were used to generate a plot of voltage in bicuculline $\left(V_{(\text {bic })}\right)$ versus control $\left(V_{(\text {con })}\right)$. Linear regression provided estimates of the slope (1.55) and intercept of this relationship and indicated a 1.55 -fold increase in gain of the population PMN inspiratory input-output relationship. The line of identity was produced by plotting $V_{(\text {con })}$ versus $V_{\text {(con) }}$.

We next tested the hypothesis that the inspiratory inhibition of PMNs originated within the Bötzinger Complex, a region in the rostral medulla that has widespread inhibitory inputs to many brainstem and spinal respiratory neurons (Fedorko and Merrill, 1984; Merrill and Fedorko, 1984). The brainstem-spinal cord preparation was pinned onto a paraffin-coated chuck in a vibratome bath, and serial sections (60-100 $\mu \mathrm{m})$ were removed in the rostrocaudal direction starting at the caudal pons. The response of $\mathrm{C} 4$ inspiratory burst amplitude to local application of bicuculline (1 $\mathrm{mm}$ ) over $\mathrm{C} 4$ was recorded after each section. Sections were fixed in $4 \%$ paraformaldehyde in $0.1 \mathrm{~m}$ phosphate buffer and stained with cresyl violet to identify structures. In the three preparations tested, complete removal of the Bötzinger Complex up to the rostral border of the pre-Bötzinger Complex had no effect on the bicuculline-mediated potentiation of $\mathrm{C} 4 \mathrm{burst}$ amplitude. Amplitude potentiation was $51 \%$ before and $56 \%$ after removal of the Bötzinger Complex. Tests of bicuculline responses after removal of more caudal structures were not performed because sectioning of the pre-Bötzinger Complex substantially reduced burst amplitude and disrupted respiratory rhythm (Fig. 10Biii) (Smith et al., 1991).

\section{DISCUSSION}

We describe an inspiratory-phase inhibitory input to PMNs that (1) reduces inspiratory output of the $\mathrm{C} 4$ nerve, (2) reduces PMN excitability during inspiration relative to expiration, (3) is mediated via $\mathrm{GABA}_{\mathrm{A}}$ receptors, (4) is unlikely to arise from recurrent inhibitory pathways or from descending inputs from the Bötz-

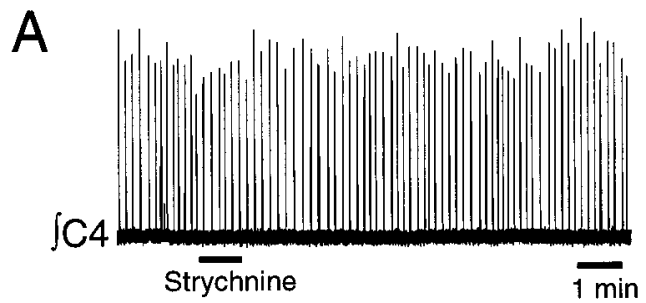

$\mathrm{B}$
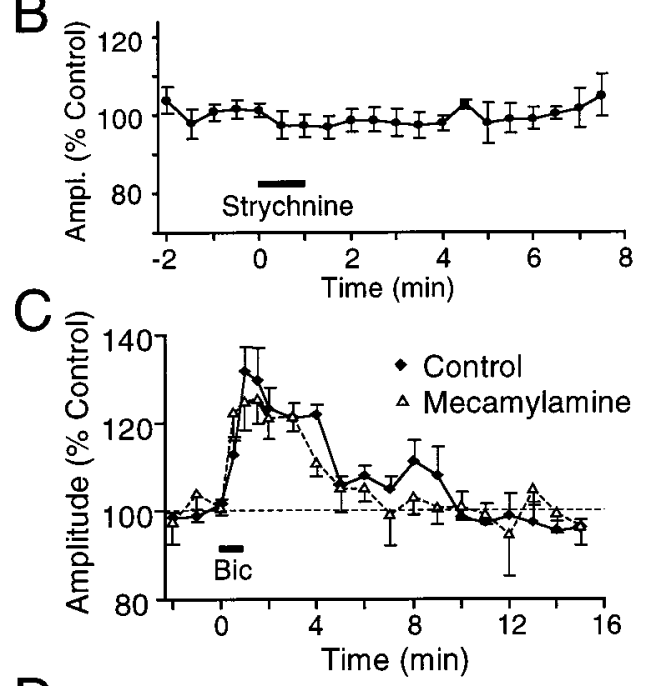

D

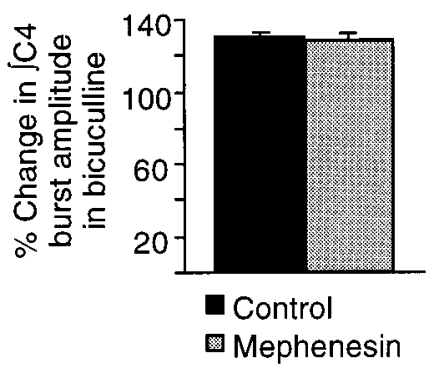

Figure 9. Renshaw cells do not mediate the bicuculline-sensitive inspiratory inhibition. $A$, Rectified, integrated record of $\mathrm{C} 4$ inspiratory activity from a P1 rat brainstem-spinal cord showing no change in nerve burst amplitude after a $60 \mathrm{sec}$ application of $1 \mathrm{~mm}$ strychnine (bar under trace) to the C4 PMN pool. $B$, Pooled data confirm that strychnine applied to the C4 PMN pool ( $60 \mathrm{sec}$ starting at $t=0$, indicated by bar) had no effect on $\mathrm{C} 4$ inspiratory output $(n=6$; mean $\pm \mathrm{SE}) . C$, Addition of mecamylamine $(50 \mu \mathrm{M})$ to the medium perfusing the spinal cord (splitbath configuration) did not block the potentiation of $\int \mathrm{C} 4$ inspiratory burst amplitude induced by local application of bicuculline $(1 \mathrm{~mm}, 60 \mathrm{sec})(n=$ 4; error bars indicate SE). $D$, Potentiation of $\mathrm{C} 4$ burst amplitude induced by local application of bicuculline ( $60 \mathrm{sec}, 1 \mathrm{~mm})$ over the PMN pool (Control) was not affected by addition of mephenesin $(1 \mathrm{~mm})$ to the spinal cord bath $(n=5$; error bars indicate $\mathrm{SE})$.

inger Complex, and (5) is synchronous with, and of similar shape to, the inspiratory excitatory drive to PMNs. We propose that this concurrent inhibition allows for rapid modulation of PMN excitability.

\section{Mechanism of inspiratory inhibition GABAergic inhibition}

Complete block of the inspiratory inhibition by bicuculline in all PMNs tested and reduction of PMN $R_{\mathrm{N}}$ and action potential discharge by GABA and muscimol indicate that the inhibition is mediated by $\mathrm{GABA}_{\mathrm{A}}$ receptors. Potentiation of $\mathrm{C} 4$ inspiratory output by bicuculline, but not strychnine, further supports the 


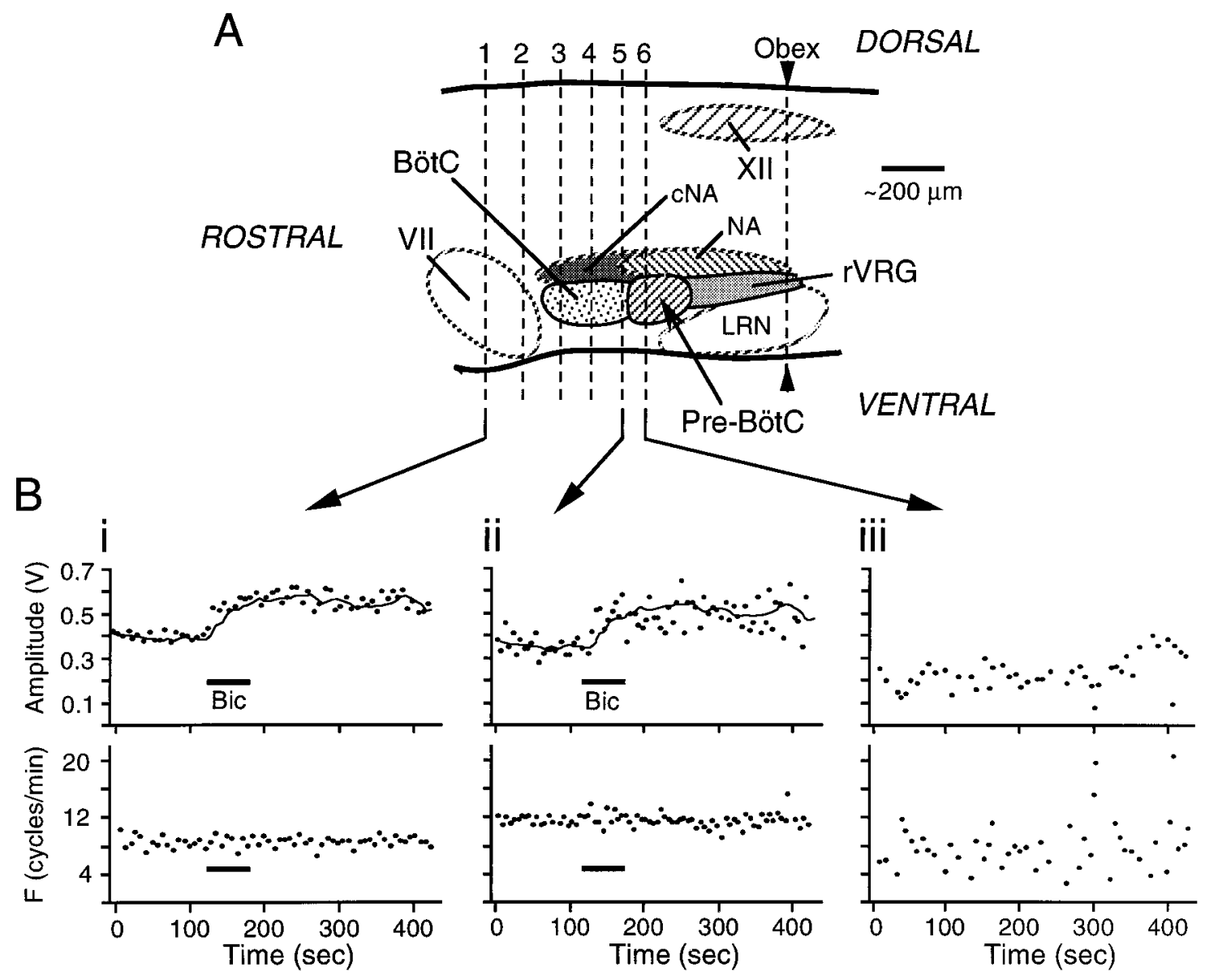

Figure 10. The inspiratory-related inhibition does not arise from structures rostral to the pre-Bötzinger Complex. $A$, Sagittal view of the brainstem showing levels of transection (dashed lines labeled 1 through 6 ) taken serially, in relation to organization of ventrolateral brainstem respiratory nuclei. $B$, Time course of the effects on $\int \mathrm{C} 4$ inspiratory burst amplitude (in volts) and burst frequency $(F)$ of locally applying bicuculline (60 sec, 1 mM) over the $\mathrm{C} 4 \mathrm{PMN}$ pool after transection of the brainstem at levels 1 (Bi) and 5 (Bii). Individual data points represent amplitude and frequency of single inspiratory cycles. The line in the top panel of $B i$ represents the moving average of the $\mathrm{C} 4$ burst amplitude response to bicuculline applied after transection at level 1. This moving average is included in Bii to illustrate that the effects of bicuculline were unaffected with progressively more caudal transections up to level 5. Removal of the rostral component of the pre-Bötzinger Complex with transection at level 6 disrupted both respiratory rhythm and C4 burst amplitude (Biii), precluding further analysis of responses to bicuculline. BötC, Bötzinger Complex; VII, facial nucleus; XII, hypoglossal nucleus; $c N A$, compact division of nucleus ambiguus; $L R N$, lateral reticular nucleus; $N A$, nucleus ambiguus; Pre-Böt $C$, pre-Bötzinger Complex; $r V R G$, rostral-ventral respiratory group).

conclusion that the inhibition is GABA-mediated, with minimal contribution of glycine receptors. The possibility that bicuculline produced its actions through direct effects (i.e., non-receptormediated), as reported in cultured mouse neurons (Heyer et al., 1982), is unlikely because bicuculline had no effect on subthreshold properties or firing behavior of PMNs during expiration. Our studies did not establish whether the GABAergic inhibition is presynaptic or postsynaptic; however, GABA receptors are present on PMNs (Zhan et al., 1989), and reduction in PMN $R_{\mathrm{N}}$ by GABA [and muscimol (Su and Chai, 1998)] after block of synaptic transmission with TTX is consistent with postsynaptic GABA receptor involvement.

\section{Recurrent inhibition}

Innervation of Renshaw cells by PMNs and the demonstration of recurrent inhibition of PMNs (Hilaire et al., 1983, 1986; Lipski et al., 1985) raise the possibility that the inspiratory inhibition arises from a recurrent inhibitory pathway. However, several lines of evidence argue against this. (1) Glycine is an important transmitter in recurrent inhibitory pathways (Curtis et al., 1976; Cullheim and Kellerth, 1981; Schneider and Fyffe, 1992), yet strychnine had no effect on C4 inspiratory output. (2) Motoneurons activate Renshaw cells primarily via nAChRs (Curtis and Ryall, 1966; Noga et al., 1987); however, nAChR antagonists neither potentiated $\mathrm{C} 4$ inspiratory burst output nor occluded its potentiation by bicuculline. (3) The inspiratory inhibition was present during prolonged application of glutamate receptor antagonists over the C4 motoneuron pool, which would have greatly reduced the number of PMNs capable of activating recurrent pathways.

\section{Descending inhibition from the brainstem: concurrent inhibition}

Given that recurrent inhibition appears minimal, we propose that the inspiratory inhibition arises from inspiratory-modulated neurons within the brainstem.

Direct bulbospinal pathways. Respiratory-modulated bulbospinal inputs to PMNs originate primarily from the Bötzinger Complex, the rostral-ventral respiratory group (rVRG), the dorsal respiratory group (DRG) and the raphe obscuris and pallidus (Fedorko and Merrill, 1984; Ellenberger et al., 1990a,b; Dobbins 
and Feldman, 1994). The Bötzinger Complex is unlikely to be the source of the inspiratory inhibition. Bötzinger Complex neurons provide expiratory- rather than inspiratory-phase inhibition to PMNs (Merrill and Fedorko, 1984; Milano et al., 1992), and in our study, removal of the Bötzinger Complex by serial sectioning was without effect on the bicuculline-mediated potentiation of $\mathrm{C} 4$ inspiratory burst amplitude.

In rat, the predominant direct inspiratory bulbospinal projection to PMNs originates from the rVRG (Ellenberger and Feldman, 1988; Ellenberger et al., 1990b; Saji and Miura, 1990; Dobbins and Feldman, 1994), with minimal contributions from the DRG (Onai et al., 1987; Dobbins and Feldman, 1994). Although data indicate that these projections are primarily excitatory (Ellenberger et al., 1990a; Tian and Duffin, 1996b), they may not be exclusively so. Some inspiratory neurons in the rVRG inhibit other respiratory neurons (Segers et al., 1987; Ezure et al., 1989; Schmid et al., 1996; Ramirez et al., 1997), and a population of inspiratory $\mathrm{rVRG}$ neurons may provide inhibitory inputs to PMNs, as suggested by the presence of a small proportion of symmetrical densities at rVRG-PMN synapses (Ellenberger et al., 1990a). Coactivation of bulbospinal inhibitory and excitatory premotoneuron pools would account for the similar time course of inhibitory and excitatory synaptic inputs we observed in PMNs.

Medullary raphe neurons may also provide the inspiratory inhibition of PMNs. Neurons in the raphe obscuris and pallidus project to the region of the phrenic nucleus (Holtman et al., 1984; Onai et al., 1987; Dobbins and Feldman, 1994) and show GAD immunoreactivity (Jones et al., 1991; Holmes et al., 1994) and respiratory-modulated activity (Lindsey et al., 1987; Hosagai et al., 1993; Gilbey et al., 1995).

Propriospinal pathways. Inspiratory phase inhibition with a profile similar to the excitatory input could arise polysynaptically. In cat spinal cord, agonist motoneurons and Ia inhibitory interneurons that inhibit antagonist motoneurons receive parallel descending synaptic drive (Baldissera et al., 1981).

Inspiratory and expiratory interneurons with unknown connectivity are located proximal to the phrenic nucleus in cat (Bellingham and Lipski, 1990; Grelot et al., 1993) and rabbit (Palisses et al., 1989). A group of interneurons $200 \mu \mathrm{m}$ from PMNs may be interposed between bulbospinal neurons and PMNs (Dobbins and Feldman, 1994). However, a role for either group in mediating the inspiratory inhibition that we observed is doubtful. Their proximity to the phrenic nucleus means that their inspiratory activation would have been greatly reduced, if not blocked, by local application of glutamatergic antagonists.

Contributions from more distant propriospinal inspiratory neurons in the upper cervical cord (Nakazono and Aoki, 1994; Tian and Duffin, 1996a) cannot be ruled out. However, mephenesin, which preferentially blocks polysynaptic versus monosynaptic transmission (Farkas et al., 1989), failed to block the bicuculline-induced potentiation of $\mathrm{C} 4$ burst amplitude when applied to the spinal cord bath, arguing against a propriospinalmediated inhibition of PMN activity.

In summary, we conclude that the inspiratory-phase inhibition of PMNs does not originate from recurrent inhibition at the level of the spinal cord or from descending Bötzinger projections. Its proposed bulbospinal origin remains to be verified.

\section{Functional significance of concurrent inhibitory and excitatory inputs}

The physiological relevance of the inspiratory inhibition of PMNs is apparent in that blocking it with bicuculline produces an $\sim 30 \%$ increase in C4 inspiratory output. This inhibition may serve a number of functions, as described below.

\section{Competing synaptic drives in the control of motoneuron excitability}

Integration of simultaneous excitatory and inhibitory synaptic inputs is important in shaping neuronal discharge patterns at the interneuronal/premotoneuronal level in various motor systems, including respiration (Ballantyne and Richter, 1984; Schmid et al., 1996; Ramirez et al., 1997). GABA receptor-mediated inhibition of medullary inspiratory neuron discharge during inspiration is well documented (Wang et al., 1982; Paton and Richter, 1995; Schmid et al., 1996; McCrimmon et al., 1997; Ramirez et al., 1997). In contrast, at the level of the motoneuron, it is generally held that excitatory and inhibitory synaptic inputs arrive alternately, not simultaneously, and thus underlie rhythmic alternation between active and quiescent phases in behaviors including scratching, locomotion, and respiration (Perret, 1983; Merrill and Fedorko, 1984; Shefchyk and Jordan, 1985; Robertson and Stein, 1988). Periods of overlap between inhibitory and excitatory synaptic inputs are typically brief and presumed to bring about phase transitions. In inspiratory-modulated hypoglossal motoneurons, however, IPSPs arrive concurrently with excitatory inspiratory drive (Withington-Wray et al., 1988), and $R_{\mathrm{N}}$ is reduced during inspiration (Woch and Kubin, 1995). These findings, in conjunction with our observation of simultaneous excitation and inhibition of PMNs during inspiration and observations of large periods of overlap between excitatory and inhibitory inputs in cat motoneurons during fictive locomotion (Perret, 1986) and in turtle motoneurons during some forms of fictive scratch (Robertson and Stein, 1988), suggest that integration of overlapping opposing synaptic inputs at the level of the motoneuron may play multiple roles in controlling motor output. It may control gain, shape discharge pattern, establish recruitment order, or smooth force production and provide greater flexibility of control (Robertson and Stein, 1998; Feldman and Smith, 1995).

\section{Phase-specific control of motoneuron excitability}

Evidence for behavioral- or phase-specific modulation of motoneuron properties is limited. Krawitz et al. (1997) showed that firing of lumbar motoneurons is enhanced during all phases of fictive locomotion. They suggest that this may result from a locomotion-related modulation of motoneuron excitability, perhaps via a mechanism similar to that which underlies bistable behavior [i.e., "plateau potentials" (see Hultborn and Kiehn, 1992)]. Brownstone et al. (1992) found that motoneuron excitability increases specifically during the active phase of the locomotor cycle and attributed this to a phase-specific reduction in afterhyperpolarization. In our study, block of rhythmic excitatory drive revealed a GABA-mediated inhibition of PMNs during the inspiratory phase. Relative to other motoneuron systems with partially overlapping inhibitory and excitatory inputs (Perret, 1983; Orsal et al., 1986; Robertson and Stein, 1988), the unique aspect of the inspiratory-phase inhibition of PMNs is that its shape and time course match those of the excitatory input (Fig. 3). It therefore provides a means for inspiratory-specific gain control of PMN output. Gain control via GABAergic inhibition may play a role in controlling the excitability of respiratory premotoneurons (McCrimmon et al., 1997), where it is proposed to contribute to the optimization of respiratory and nonrespiratory behaviors. A similar mechanism may operate at the motoneuron level. Inspiratory inhibition may arise from neurons that provide the 
interface between respiratory and nonrespiratory behavior (Orem, 1989), and modulation of its amplitude may adjust PMN output from that optimal for respiration to that suited to other behaviors such as apnea, gasping, coughing, vocalization, or defecation (Chang, 1992; Grelot et al., 1992; Gestreau et al., 1996).

\section{REFERENCES}

Baldissera F, Hultborn H, Illert M (1981) Integration in spinal neuronal systems. In: Handbook of physiology, Section I, The nervous system, Vol II, Motor control, Part I, (Brooks VB, ed), pp 509-595. Bethesda, MD: American Physiological Society.

Ballantyne D, Richter DW (1984) Post-synaptic inhibition of bulbar inspiratory neurones in the cat. J Physiol (Lond) 348:67-87.

Bellingham MC, Lipski J (1990) Respiratory interneurons in the C5 segment of the spinal cord of the cat. Brain Res 533:141-146.

Berger AJ, Bayliss DA, Viana F (1996) Development of hypoglossal motoneurons. J Appl Physiol 81:1039-1048.

Blanton MG, Lo Turco JJ, Kriegstein AR (1989) Whole cell recording from neurons in slices of reptilian and mammalian cerebral cortex. J Neurosci Methods 30:203-210.

Brownstone RM, Jordan LM, Kriellaars DJ, Noga BR, Shefchyk SJ (1992) On the regulation of repetitive firing in lumbar motoneurones during fictive locomotion in the cat. Exp Brain Res 90:441-455.

Chang F-CT (1992) Modification of medullary respiratory-related discharge patterns by behaviors and states of arousal. Brain Res 571:281-292.

Connelly CA, Otto-Smith MR, Feldman JL (1992) Blockade of NMDA receptor-channels by MK-801 alters breathing in adult rats. Brain Res 596:99-110.

Cullheim S, Kellerth JO (1981) Two kinds of recurrent inhibition of cat spinal alpha-motoneurones as differentiated pharmacologically. J Physiol (Lond) 312:209-224.

Curtis DR, Ryall RW (1966) The synaptic excitation of Renshaw cells. Exp Brain Res 2:81-96.

Curtis DR, Game CJ, Lodge D, McCulloch RM (1976) A pharmacological study of Renshaw cell inhibition. J Physiol (Lond) 258:227-242.

Dickinson PS (1995) Interaction among neural networks for behavior. Curr Opin Neurobiol 5:792-798.

Dobbins EG, Feldman JL (1994) Brainstem network controlling descending drive to phrenic motoneurons in rat. J Comp Neurol 347:64-86.

Dong X-W, Feldman JL (1995) Modulation of inspiratory drive to phrenic motoneurons by presynaptic adenosine A1 receptors. J Neurosci 15:3458-3467.

Dong X-W, Feldman J (1996) Role and mechanism of endogenously activated mGluR1 in modulating synaptic transmission to phrenic motoneurons. Soc Neurosci Abstr 22:598.

Ellenberger HH, Feldman JL (1988) Monosynaptic transmission of respiratory drive to phrenic motoneurons from brainstem bulbospinal neurons in rats. J Comp Neurol 269:47-57.

Ellenberger HH, Feldman JL, Goshgarian HG (1990a) Ventral respiratory group projections to phrenic motoneurons: electron microscopic evidence for monosynaptic connections. J Comp Neurol 302:707-714.

Ellenberger HH, Vera PL, Haselton JR, Haselton CL, Schneiderman N (1990b) Brainstem projections to the phrenic nucleus: an anterograde and retrograde HRP study in the rabbit. Brain Res Bull 24:163-174.

Ezure K, Manabe M, Otake K (1989) Excitation and inhibition of medullary inspiratory neurons by two types of burst inspiratory neurons in the cat. Neurosci Lett 104:303-308.

Farkas S, Tarnawa I, Berzsenyi P (1989) Effects of some centrally acting muscle relaxants on spinal root potentials: a comparative study. Neuropharmacology 28:161-173.

Fedorko L, Merrill EG (1984) Axonal projections from the rostral expiratory neurones of the Botzinger complex to medulla and spinal cord in the cat. J Physiol (Lond) 350:487-496.

Feldman JL, Smith JC (1995) Neural control of respiratory pattern in mammals: an overview. In: Regulation of breathing, Vol 79 (Dempsey JA, Pack AI, eds), pp 39-69. New York: M. Dekker.

Feldman JL, Smith JC, Ellenberger HH, Connelly CA, Liu G, Greer JJ, Lindsay AD, Otto MR (1990) Neurogenesis of respiratory rhythm and pattern: emerging concepts. Am J Physiol 259:R879-R886.

Gestreau C, Milano S, Bianchi AL, Grelot L (1996) Activity of dorsal respiratory group inspiratory neurons during laryngeal-induced fictive coughing and swallowing in decerebrate cats. Exp Brain Res 108:247-256.

Gilbey MP, Futuro-Neto HA, Zhou SY (1995) Respiratory-related discharge patterns of caudal raphe neurones projecting to the upper thoracic spinal cord in the rat. J Auton Nerv Syst 50:263-273.

Greer JJ, Smith JC, Feldman JL (1991) Role of excitatory amino acids in the generation and transmission of respiratory drive in neonatal rat. J Physiol (Lond) 437:727-749.

Grelot L, Milano S, Portillo F, Miller AD, Bianchi AL (1992) Membrane potential changes of phrenic motoneurons during fictive vomiting, coughing, and swallowing in the decerebrate cat. J Neurophysiol 68:2110-2119.

Grelot L, Milano S, Portillo F, Miller AD (1993) Respiratory interneurons of the lower cervical $(\mathrm{C} 4-\mathrm{C} 5)$ cord: membrane potential changes during fictive coughing, vomiting, and swallowing in the decerebrate cat. Pflügers Arch 425:313-320.

Heyer EJ, Nowak LM, Macdonald RL (1982) Membrane depolarization and prolongation of calcium-dependent action potentials of mouse neurons in cell culture by two convulsants: bicuculline and penicillin. Brain Res 232:41-56.

Hilaire G, Khatib M, Monteau R (1983) Spontaneous respiratory activity of phrenic and intercostal Renshaw cells. Neurosci Lett 43:97-101.

Hilaire G, Khatib M, Monteau R (1986) Central drive on Renshaw cells coupled with phrenic motoneurons. Brain Res 376:133-139.

Holmes CJ, Mainville LS, Jones BE (1994) Distribution of cholinergic GABAergic and serotonergic neurons in the medial reticular formation and their projections studied by cytotoxic lesions in the cat. Neuroscience 62:1155-1178.

Holtman Jr JR, Norman WP, Gillis RA (1984) Projections from the raphe nuclei to the phrenic motor nucleus in the cat. Neurosci Lett 44:105-111.

Hosagai M, Matsuo S, Nakao S (1993) Firing pattern and location of respiratory neurons in cat medullary raphe nuclei. Neurosci Lett 161:149-152.

Hounsgaard J, Kiehn O (1989) Serotonin-induced bistability of turtle motoneurones caused by a nifedipine-sensitive calcium plateau potential. J Physiol (Lond) 414:265-282.

Hounsgaard J, Hultborn H, Jespersen B, Kiehn O (1988) Bistability of alpha-motoneurones in the decerebrate cat and in the acute spinal cat after intravenous 5-hydroxytryptophan. J Physiol (Lond) 405:345-367.

Hultborn H, Kiehn O (1992) Neuromodulation of vertebrate motor neuron membrane properties. Curr Opin Neurobiol 2:770-775.

Hultborn H, Lindstrom S, Wigstrom H (1979) On the function of recurrent inhibition in the spinal cord. Exp Brain Res 37:399-403.

Jones BE, Holmes CJ, Rodriguez-Veiga E, Mainville L (1991) GABAsynthesizing neurons in the medulla: their relationship to serotonincontaining and spinally projecting neurons in the rat. J Comp Neurol 313:349-367.

Krawitz S, Fedirchuk B, Dai Y, Jordan LM, McCrea DA (1997) Locomotion hyperpolarizes the voltage threshold of cat lumbar motoneurones. Soc Neurosci Abstr 23:759.

Kubin L, Kimura H, Tojima H, Davies RO, Pack AI (1993) Suppression of hypoglossal motoneurons during the carbachol-induced atonia of REM sleep is not caused by fast synaptic inhibition. Brain Res 611:300-312.

Lindsey BG, Segers LS, Shannon R (1987) Functional associations among simultaneously monitored lateral medullary respiratory neurons in the cat. II. Evidence for inhibitory actions of expiratory neurons. J Neurophysiol 57:1101-1117.

Lipski J, Fyffe RE, Jodkowski J (1985) Recurrent inhibition of cat phrenic motoneurons. J Neurosci 5:1545-1555.

Liu G, Feldman JL, Smith JC (1990) Excitatory amino acid-mediated transmission of inspiratory drive to phrenic motoneurons. J Neurophysiol 64:423-436.

McCrimmon DR, Zuperku EJ, Hayashi F, Dogas Z, Hinrichsen CF, Stuth EA, Tonkovic-Capin M, Krolo M, Hopp FA (1997) Modulation of the synaptic drive to respiratory premotor and motor neurons. Respir Physiol 110:161-176.

Merrill EG, Fedorko L (1984) Monosynaptic inhibition of phrenic motoneurons: a long descending projection from Botzinger neurons. J Neurosci 4:2350-2353.

Milano S, Miller AD, Grelot L (1992) Multi-phase expiratory inhibition of phrenic motoneurons in the decerebrate cat. NeuroReport 3:307-310.

Nakazono Y, Aoki M (1994) Excitatory connections between upper 
cervical inspiratory neurons and phrenic motoneurons in cats. J Appl Physiol 77:679-683.

Noga BR, Shefchyk SJ, Jamal J, Jordan LM (1987) The role of Renshaw cells in locomotion: antagonism of their excitation from motor axon collaterals with intravenous mecamylamine. Exp Brain Res 66:99-105.

Onai T, Saji M, Miura M (1987) Projections of supraspinal structures to the phrenic motor nucleus in rats studied by a horseradish peroxidase microinjection method. J Auton Nerv Syst 21:233-239.

Orem J (1989) Behavioral inspiratory inhibition: inactivated and activated respiratory cells. J Neurophysiol 62:1069-1078.

Orsal D, Perret C, Cabelguen JM (1986) Evidence of rhythmic inhibitory synaptic influences in hindlimb motoneurons during fictive locomotion in the thalamic cat. Exp Brain Res 64:217-224.

Palisses R, Persegol L, Viala D (1989) Evidence for respiratory interneurones in the $\mathrm{C} 3-\mathrm{C} 5$ cervical spinal cord in the decorticate rabbit. Exp Brain Res 78:624-632.

Paton JFR, Richter DW (1995) Role of fast inhibitory synaptic mechanisms in respiratory rhythm generation in the maturing mouse. J Physiol (Lond) 484:505-521.

Perret C (1983) Centrally generated pattern of motoneuron activity during locomotion in the cat. Symp Soc Exp Biol 37:405-422.

Perret C (1986) Synaptic influences contributing to the pattern of limb motoneuron activity during fictive locomotion in the cat. In: Neurobiology of vertebrate locomotion (Grillner S, Stein PSG, Stuart DG, Forsberg H, Hermann RM, eds), pp 173-184. Basingstroke, UK: Macmillan.

Ramirez JM, Telgkamp P, Elsen FP, Quellmalz UJ, Richter DW (1997) Respiratory rhythm generation in mammals: synaptic and membrane properties. Respir Physiol 110:71-85.

Robertson GA, Stein PS (1988) Synaptic control of hindlimb motoneurones during three forms of the fictive scratch reflex in the turtle. J Physiol (Lond) 404:101-128.

Saji M, Miura M (1990) Evidence that glutamate is the transmitter mediating respiratory drive from medullary premotor neurons to phrenic motoneurons: a double labeling study in the rat. Neurosci Lett 115:177-182.

Schmid K, Foutz AS, Denavit-Saubie M (1996) Inhibitions mediated by glycine and GABAA receptors shape the discharge pattern of bulbar respiratory neurons. Brain Res 710:150-160.
Schneider SP, Fyffe RE (1992) Involvement of GABA and glycine in recurrent inhibition of spinal motoneurons. J Neurophysiol 68:397-406.

Segers LS, Shannon R, Saporta S, Lindsey BG (1987) Functional associations among simultaneously monitored lateral medullary respiratory neurons in the cat. I. Evidence for excitatory and inhibitory actions of inspiratory neurons. J Neurophysiol 57:1078-1100.

Shefchyk SJ, Jordan LM (1985) Excitatory and inhibitory postsynaptic potentials in $\alpha$-motoneurons produced during fictive locomotion by stimulation of the mesencephalic locomotor region. J Neurophysiol 53:1345-1355.

Smith JC, Feldman JL (1987) In vitro brainstem-spinal cord preparations for study of motor systems for mammalian respiration and locomotion. J Neurosci Methods 21:321-333.

Smith JC, Ellenberger HH, Ballanyi K, Richter DW, Feldman JL (1991) Pre-Botzinger complex: a brainstem region that may generate respiratory rhythm in mammals. Science $254: 726-729$.

Soja PJ, Lopez-Rodriguez F, Morales FR, Chase MH (1991) The postsynaptic inhibitory control of lumbar motoneurons during the atonia of active sleep: effect of strychnine on motoneuron properties. J Neurosci 11:2804-2811.

Su C-K, Chai C-Y (1998) GABAergic inhibition of neonatal phrenic motoneurons. Neurosci Lett 248:191-194.

Tian GF, Duffin J (1996a) Connections from upper cervical inspiratory neurons to phrenic and intercostal motoneurons studied with crosscorrelation in the decerebrate rat. Exp Brain Res 110:196-204.

Tian GF, Duffin J (1996b) Spinal connections of ventral-group bulbospinal inspiratory neurons studied with cross-correlation in the decerebrate rat. Exp Brain Res 111:178-186.

Wang L, Boyarsky LL, Frazier DT (1982) The effect of transmitter antagonists on phasic respiratory neurons. J Neurosci Res 8:657-664.

Withington-Wray DJ, Mifflin SW, Spyer KM (1988) Intracellular analysis of respiratory-modulated hypoglossal motoneurons in the cat. Neuroscience 25:1041-1051.

Woch G, Kubin L (1995) Non-reciprocal control of rhythmic activity in respiratory-modulated XII motoneurons. NeuroReport 6:2085-2088.

Zhan WZ, Ellenberger HH, Feldman JL (1989) Monoaminergic and GABAergic terminations in phrenic nucleus of rat identified by immunohistochemical labeling. Neuroscience 31:105-113. 